\title{
Optical Properties of Transparent Rare-Earth Doped Sol-Gel Derived Nano-Glass Ceramics
}

\author{
Mihail Secu*, Corina Secu and Cristina Bartha (D) \\ National Institute of Materials Physics, 077125 Magurele, Romania; cesecu@infim.ro (C.S.); \\ cristina.bartha@infim.ro (C.B.) \\ * Correspondence: msecu@infim.ro
}

check for updates

Citation: Secu, M.; Secu, C.; Bartha, C. Optical Properties of Transparent Rare-Earth Doped Sol-Gel Derived Nano-Glass Ceramics. Materials 2021, 14, 6871. https://doi.org/10.3390/ ma14226871

Academic Editor: Edgar

Dutra Zanotto

Received: 1 October 2021

Accepted: 9 November 2021

Published: 14 November 2021

Publisher's Note: MDPI stays neutral with regard to jurisdictional claims in published maps and institutional affiliations.

Copyright: (c) 2021 by the authors. Licensee MDPI, Basel, Switzerland. This article is an open access article distributed under the terms and conditions of the Creative Commons Attribution (CC BY) license (https:// creativecommons.org/licenses/by/ $4.0 /)$.

\begin{abstract}
Rare-earth doped oxyfluoride glass ceramics represent a new generation of tailorable optical materials with high potential for optical-related applications such as optical amplifiers, optical waveguides, and white LEDs. Their key features are related to the high transparency and remarkable luminescence properties, while keeping the thermal and chemical advantages of oxide glasses. Sol-gel chemistry offers a flexible synthesis approach with several advantages, such as lower processing temperature, the ability to control the purity and homogeneity of the final materials on a molecular level, and the large compositional flexibility. The review will be focused on optical properties of sol-gel derived nano-glass ceramics related to the RE-doped luminescent nanocrystals (fluorides, chlorides, oxychlorides, etc.) such as photoluminescence, up-conversion luminescence, thermoluminescence and how these properties are influenced by their specific processing, mostly focusing on the findings from our group and similar ones in the literature, along with a discussion of perspectives, potential challenges, and future development directions.
\end{abstract}

Keywords: sol-gel; glass ceramic; nanocrystals; fluorides; rare-earth; luminescence

\section{Introduction}

Glass ceramics are inorganic, non-metallic materials prepared by controlled crystallization of precursor glasses with at least one type of functional crystalline phase, that may vary from ppm to almost $100 \%$ is embedded in residual glass [1]. The basic requirements for optical transparency include: nanocrystals size smaller than the light wavelength, very close refractive index of amorphous and crystalline phases and low birefringency [1]. Transparent oxyfluoride nano-glass ceramics are produced by fluoride nanocrystals precipitation in a silica glass matrix during a controlled thermal processing. They have shown a high potential for applications in various devices (optical amplifiers, optical waveguides, white LEDs, etc.) since they combine the optical phenomena with optical transparency due to lack of scattering.

The conventional way to obtain glass ceramics is by melt-quenching (at around $1400{ }^{\circ} \mathrm{C}$ for oxy-fluoride glasses or a lower temperature in a controlled atmosphere for fluoride glasses) followed by crystallization of the precursor glass during a controlled annealing step throughout a heat-treatment at lower temperatures. Nucleation and growth of fluoride nanocrystals occurs in the glass matrix during heat treatment and rare earth ions can preferentially segregate into the fluoride nanocrystals. Hence, the partition of the optically active rare-earth (RE) ions into the precipitated fluoride nanocrystals can be obtained, with low phonon frequencies, but keeping good chemical and mechanical stability of the oxide glass (see the review of de Pablos-Martin et al. [2]). An alternative route is based on sol-gel chemistry, well known as a flexible approach to preparing various materials such as glass, ceramics, and organic-inorganic hybrids by using colloidal solutions (sol) as starting materials [3,4]. The glass ceramics' synthesis by using the sol-gel method has several advantages such as lower processing temperature, the ability to control the purity and homogeneity of the final materials on a molecular level, and the large compositional 
flexibility which could be difficult to obtain via the melt-quenching technique. Most of the sol-gel derived oxyfluoride glass ceramic materials studied have a simple composition according to the formula: $(100-\mathrm{x}) \mathrm{SiO}_{2}-\mathrm{xM}_{1} \mathrm{~F}_{2} / \mathrm{M}_{2} \mathrm{~F}_{3} / \mathrm{M} 1 \mathrm{M} 2 \mathrm{~F}_{4}$, where $\mathrm{M} 1$ and $\mathrm{M} 2$ are alkaline, alkaline-earth metals, or lanthanide elements, respectively [4].

This review is focused on luminescence properties of sol-gel derived nano-glass ceramics related to the RE-doped luminescent nanocrystals (fluorides, chlorides, oxychlorides, etc.) such as photoluminescence, up-conversion luminescence, thermoluminescence and how these properties are influenced by thermal processing, focusing on the findings from our group and similar ones in the literature of the past decade, along with a discussion of the future perspectives, potential challenges, and future development directions.

\section{Sol-Gel Method for Glass Ceramic Synthesis}

The pioneering contribution on sol-gel derived oxyfluoride glass ceramic preparation came from the first works of Fujihara et al. [5-7] performed in two steps: (i) preparation of a silica sol by using classic route with metal alkoxides (ii) followed by mixing with a second trifluoroacetates solution formed by trifluoroacetic (TFA) acid reaction with rare earth precursors (acetates). The liquid mixture is dried and aged at room temperature under sealed containers for several days or weeks. The nanocrystalline phase precipitation is obtained during subsequent calcination of dried xerogel matrix above the temperature required for thermal decomposition of corresponding trifluoracetates at around $300{ }^{\circ} \mathrm{C}$ :

$$
\mathrm{RE}\left(\mathrm{CF}_{3} \mathrm{COO}\right)_{3} \rightarrow \mathrm{REF}_{3}+\left(\mathrm{CF}_{3} \mathrm{CO}\right)_{2} \mathrm{O}+\mathrm{CO}+\mathrm{CO}_{2}
$$

Since then, the number of the publications on that topic has increased steadily and many compositions and crystalline phases have been studied using different $\operatorname{Ln}^{3+}$ ions as dopants to obtain enhanced linear and nonlinear optical processes for a wide application range.

\subsection{Crystallization Mechanism}

The first investigations of the crystallization processes of sol-gel derived glasses were done by Fujihara et al., with $\mathrm{MgF}_{2}$ thin films synthesis from trifluoracetic acid (TFA) and Mg-ethoxide $\left(\mathrm{Mg}\left(\mathrm{OC}_{2} \mathrm{H}_{5}\right)_{2}\right.$ as precursors. It was assumed that the $\mathrm{Mg}^{2+}$ ions released during the thermal decomposition of the $\mathrm{Mg}\left(\mathrm{OC}_{2} \mathrm{H}_{5}\right)_{2}$ complexes form the xerogel and react with thermally activated fluorine in $\mathrm{CF}_{3} \mathrm{COO}^{-}$ions to form $\mathrm{MgF}_{2}$ crystals [7].

The investigations of the $\mathrm{SiO}_{2}-\mathrm{LaF}_{3}$ sol gel system evolution during the heat treatment by using Fourier transform infrared spectroscopy (FTIR) analysis indicated decomposition of trifluoroacetic acid (TFA), used as a fluorine precursor, together with the formation of fluoride lattice bonding [5,6] (Figure 1). The formation of $\mathrm{LaF}_{3}$ nanocrystals (of about $10 \pm 30 \mathrm{~nm}$ in size after calcination above $300{ }^{\circ} \mathrm{C}$ of the precursor silica xerogel) was assigned to the screening effect of the $\mathrm{CF}_{3} \mathrm{COO}^{-}$ions coordinating the $\mathrm{La}^{3+}$ ions that prevented the $\mathrm{La}^{3+}$ ions incorporation into the $\mathrm{SiO}_{2}$ matrix [5]. The smallness of the $\mathrm{LaF}_{3}$ nanocrystals (tens of $\mathrm{nm}$ size) even for higher temperatures calcination was assigned to the low nanocrystals growth rate because of the uniform distribution of the nanocrystals [5]. For higher annealing temperatures above $800{ }^{\circ} \mathrm{C}$, the formation of $\mathrm{LaF}_{3}, \mathrm{La}_{2} \mathrm{O}_{3}$, and $\mathrm{LaOF}$ nanocrystals was observed [5].

Later on, the studies of the crystallization kinetics of sol gel-derived glasses were extended by using multiple techniques (structural, magnetic, optical), which indicated a decomposition chemical reaction accompanied by the precipitation of nanocrystals, and not a diffusion-controlled nucleation and growing process, as in the melt-quenched glasses [6-10]. For longer treatment times, the loss of crystal structure and a partial/total dissolution of crystals in the glass matrix was observed. Higher annealing temperature does not result in better crystallinity or bigger nanocrystals but for even higher temperatures $\left(1000{ }^{\circ} \mathrm{C}\right)$ the $\mathrm{Si}-\mathrm{O}-\mathrm{Si}$ network is heavily destroyed due to precipitation of the $\mathrm{SiO}_{2}$ crystalline phase, so the nano-crystals size grow quickly [11]. It was shown that the nanocrystal growth process in the glass matrix is strongly influenced by the ionic environment and 
ionic impurities incorporated during the growth process, and energy dispersive $\mathrm{X}$-ray (EDX) analysis indicated the presence of oxygen ions in the nanocrystals [12].

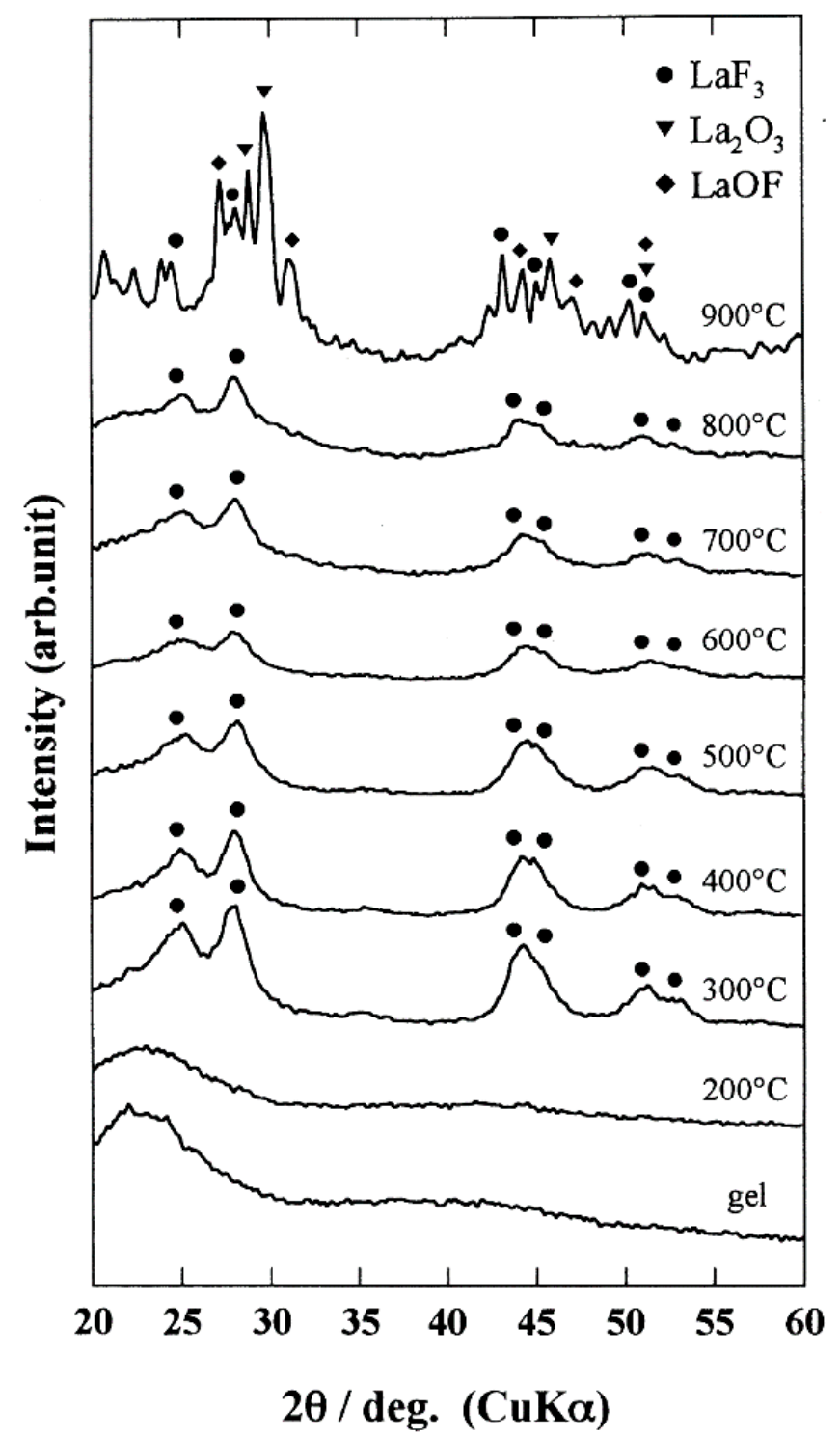

Figure 1. The XRD patterns of $\mathrm{SiO}_{2}-\mathrm{LaF}_{3}$ gel and glass ceramics obtained after calcination at different temperatures. (Reproduced from reference [5].)

Structural and morphological studies of the crystallization mechanism [13] of the $\mathrm{SiO}_{2}-\mathrm{YF}_{3}$ glass ceramic showed that the crystallization of $\mathrm{YF}_{3}$ nanocrystalline phase is due to decomposition of $\mathrm{Y}\left(\mathrm{CF}_{3} \mathrm{COO}\right)_{3}$, according to the previous image of the crystallization mechanism. Moreover, transmission electron microscopy (TEM) investigations showed that $\mathrm{YF}_{3}$ nanophase crystallization started with formation of big congeries particles in the glassy matrix consisting of many randomly oriented mono-crystallites sized around $5 \mathrm{~nm}$ (Figure 2). Higher calcination temperature (up to $600{ }^{\circ} \mathrm{C}$ ) promotes the separation of the initial nanocrystals by reducing stress and lowering system energy. A similar conclusion was reached by Yunlong Yu et al. (2006) [11], who showed that the formation of $\mathrm{SrF}_{2}$ nanocrystals $8-10 \mathrm{~nm}$ distributed homogenously among the glassy matrix. The nanocrystals size remains almost unchanged up to $800^{\circ} \mathrm{C}$ annealing due to the interfacial interaction of $\mathrm{SrF}_{2}$ nano-crystals with the glass matrix, which hinders their further growth. 

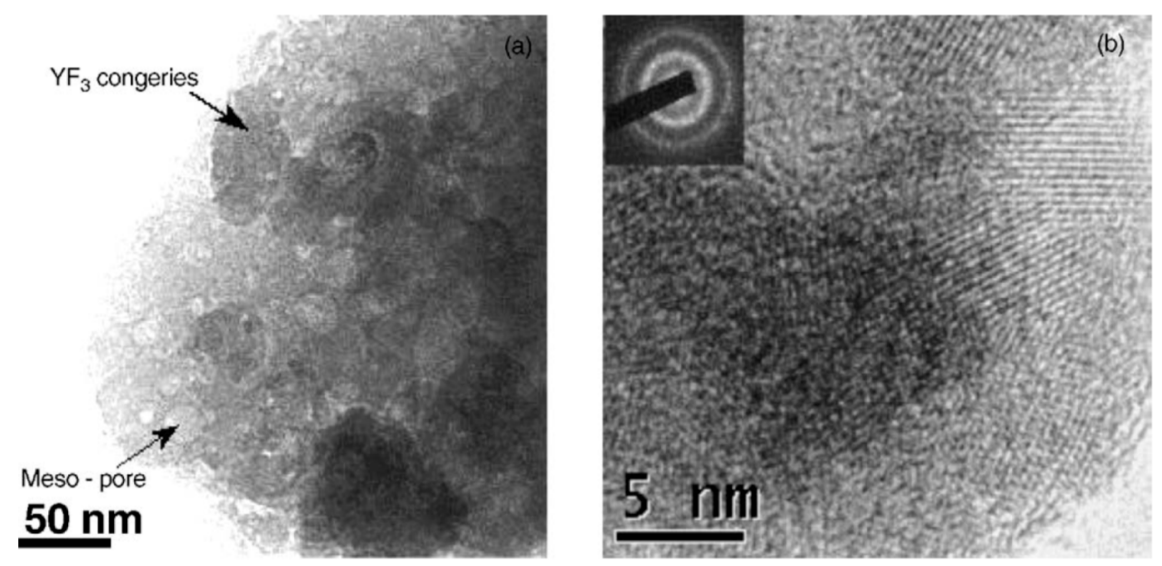

Figure 2. TEM images of the $\mathrm{SiO}_{2}-\mathrm{YF}_{3}$ xerogel sample calcinated at $400{ }^{\circ} \mathrm{C}$ (left) showing the congeries (right) (reproduced from reference [12]).

Structural and optical investigations of the crystallization process in $\mathrm{SiO}_{2}-\mathrm{BaF}_{2}$ solgel indicated a homogenous crystallization mechanism, with $\mathrm{BaF}_{2}$ small nanocrystals (a few $\mathrm{nm}$ size) acting as nucleation centers that resulted from thermal decomposition of Ba-trifluoroacetate at about $300{ }^{\circ} \mathrm{C}$ [8]. The investigations of thermal behavior of the silicate xerogels by using differential scanning calorimetry (DSC) and thermogravimetry (TG) showed a three-stage thermal degradation profile related to the glass ceramization process [8] (Figure 3). The first step corresponding to the temperature range from $120^{\circ} \mathrm{C}$ to $200{ }^{\circ} \mathrm{C}$ is due to the removal of volatile components. A second step from 280 to $360^{\circ} \mathrm{C}$ is closely related to the $\mathrm{Ba}$ trifluoroacetate decomposition [14] with the formation of tiny $\mathrm{BaF}_{2}$ nanocrystalline seeds (few $\mathrm{nm}$ size) and is accompanied by a strong DSC peak at about $307^{\circ} \mathrm{C}$. The next weight loss in the TG curve occurs in the temperature range from 400 to $500{ }^{\circ} \mathrm{C}$ and is due to the pyrolysis of organic groups bonded to silicon (residual organics and carbon). The formation of the $\mathrm{BaF}_{2}$ nanocrystalline phase in $\mathrm{Eu}^{3+}$-doped $\mathrm{SiO}_{2}-\mathrm{BaF}_{2}$ and crystallinity improvement was associated to a broad and weak DSC peak at $685{ }^{\circ} \mathrm{C}$ (Figure 3) and shows a slight dependence (within few degrees) on the RE-dopant ions incorporation. A similar peak was reported at $663{ }^{\circ} \mathrm{C}$ in $95 \mathrm{SiO}_{2}-5 \mathrm{CaF}_{2}[15]$ and at $700{ }^{\circ} \mathrm{C}$ in $95 \mathrm{SiO}_{2}-5 \mathrm{SrF}_{2}$ [11] xerogel, but not in the undoped one, indicating its strong relation to the nature of the nanocrystalline phase.

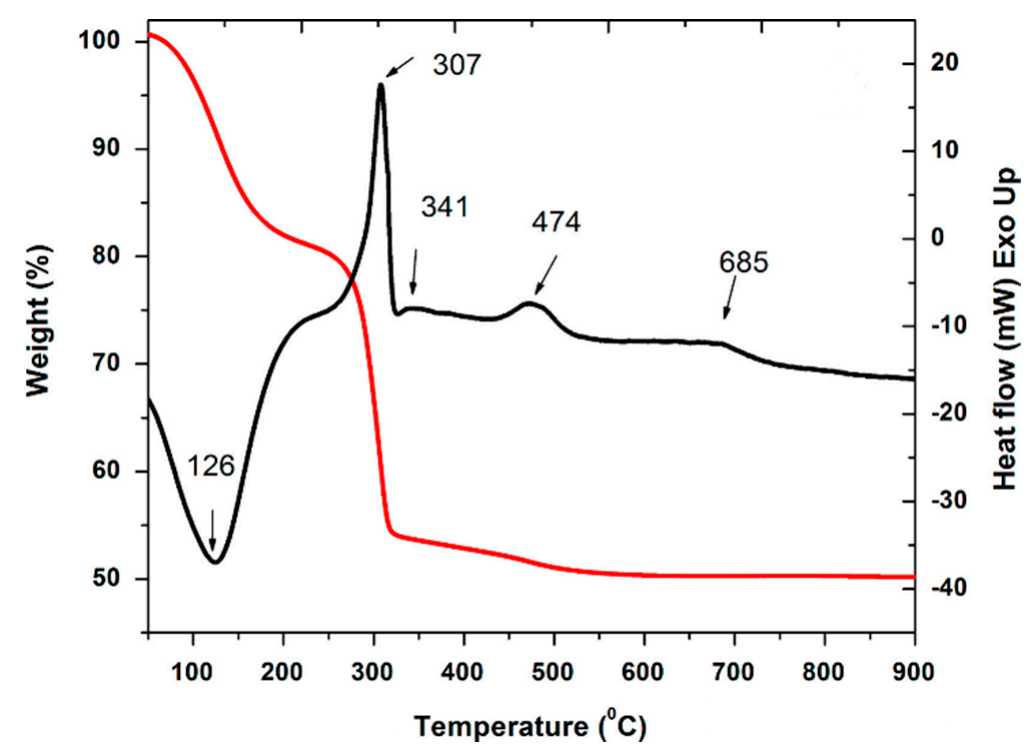

Figure 3. Thermal analysis of Eu-doped $\mathrm{SiO}_{2}-\mathrm{BaF}_{2}$ xerogel showing the TG (red) and DSC (black) curves (reproduced from reference [8]). 
Therefore, the general characteristic of the sol-gel glasses crystallization process is the thermal decomposition reaction of the metal trifluoroacetates, revealed as a strong DSC peak between 280 and $350{ }^{\circ} \mathrm{C}[10,16]$. Higher calcination temperature results in a weak increase of the nanocrystals size by promoting the separation and growth of the initial nanocrystals [13]. These processes are revealed by a second and weaker DSC peak, which is strongly dependent of the fluoride nanocrystals nature. However, the mechanism is expected to be more complicated for glass ceramics containing complex compounds such as $\mathrm{NaYF}_{4}, \mathrm{NaLaF}_{4}, \mathrm{NaGdF}_{4}, \mathrm{KLaF}_{4}, \mathrm{KYF}_{4}, \mathrm{LiYF}_{4}, \mathrm{BaYF}_{5}$, and $\mathrm{BaGdF}_{5}$ (refer to the next section).

\subsection{Optical Properties: Photoluminescence, Up-Conversion Luminescence, and Thermoluminescence}

The calcination of dried xerogel affects not only structural and morphological properties (i.e., nanocrystals formation), but also the optical ones. During xerogel calcination, a silica network is formed due to the progressive enhancement of dehydration-condensation reactions $[8,15,17]$, accompanied by the precipitation of the fluoride nanocrystalline phase, where a fraction of the $\mathrm{RE}^{3+}$ ions was incorporated. It was shown that in $\mathrm{Er}^{3+}$-doped $\mathrm{SiO}_{2}-\mathrm{LaF}_{3}$ sol-gel glass ceramic the effective concentration of rare-earth ions estimated by $\mathrm{X}$-ray absorption spectroscopy was $91 \%$ and $9 \%$ in a fluoride and glass environment, respectively [18].

In the amorphous matrix, the $\mathrm{RE}^{3+}$-ions dopants are distributed within the amorphous structure of the glass, characterized by unregular arrangement of the constituent ions. Hence, in the glass matrix, the photoluminescence spectra of the $\mathrm{RE}^{3+}$-ions shows broadening due to the random positions and random surroundings of the dopant ions. The new luminescence features observed in the glass ceramic were assigned to the $\mathrm{RE}^{3+}$ ions incorporated into the precipitated nanocrystals. The luminescence spectra in the glass ceramic shows Stark splitting due to the degeneracy lifting by the local crystal field where the $\mathrm{RE}^{3+}$-ion are incorporated, an effect clearly observed for $\mathrm{Eu}^{3+}$ ions $[19,20]$; Figure 4. Because of the nanocrystals smallness in the glass ceramic, the nanosize-related effects can have a strong influence on the PL spectra (i.e., broadening effects), as was observed in the nanocrystals [21,22]. Moreover, on the nanocrystals surface, we expect a high concentration of surface atoms and defects $[21,22]$ acting as trapping centers and non-radiatively dissipating energy. Therefore, the PL spectra are assigned to a superposition between the $\mathrm{RE}^{3+}$ ions emission located in the glass matrix and in the crystalline phase, inside the nanocrystals and on their surface [19]. Photoluminescence decay measurements are also highly sensitive to the $\mathrm{RE}^{3+}$-ions environment. Lower phonon energy of fluorides and the dehydration processes reduce the probability of non-radiative de-excitations and as a result a luminescence signal enhancement and longer luminescence lifetimes compared to the xerogels were observed $[8,18,23]$. Defects with relatively large vibration energies like hydroxyl groups from the water, solvent, and silanol groups are efficient non-radiative relaxation channels for the excited states and therefore multiphonon relaxation rate is rather large, thereby decreasing the luminescence lifetime and efficiency.

Among the $\mathrm{RE}^{3+}$ ions, $\mathrm{Eu}^{3+}$ ions are widely used as green-red light emitting activators, where the characteristic luminescence properties are to the intra-configurational $4 \mathrm{f}^{6}-4 \mathrm{f}^{6}$ transitions $\left({ }^{5} \mathrm{D}_{0} \rightarrow{ }^{7} \mathrm{~F}_{\mathrm{J}}, J=0-4\right)$; see Figure 4 . Moreover, they are widely studied as probe-ions for local site symmetry in various materials $[24,25]$ and have been used to investigate the sol-gel process $[8,26-28]$. The electric-dipole ${ }^{7} \mathrm{D}_{0} \rightarrow{ }^{5} \mathrm{~F}_{2}$ transition is sensitive to the environment and therefore the intensity ratio between the two visible emissions ${ }^{5} \mathrm{D}_{0}-{ }^{7} \mathrm{~F}_{2} /{ }^{5} \mathrm{D}_{0}-{ }^{7} \mathrm{~F}_{1}$ is highly dependent on the Eu ${ }^{3+}$-ion environment. The lower this ratio, the closer is the local symmetry to the one having an inversion center [29]. In particular, the intensity ratio has been used to monitor and discuss the sol-gel process and xerogel transformation in various $\mathrm{Eu}^{3+}$-doped glass ceramics $[8,20,23,30]$. Moreover, luminescence spectra recorded under proper excitation wavelengths and luminescence decay measurements recorded in $\mathrm{SiO}_{2}-\mathrm{LaF}_{3}$ glass ceramic have allowed discerning between ions residing in precipitated nanocrystals and those remaining in a glassy environment [23]. The $464 \mathrm{~nm}$ 
excitation wavelength is inhibited for $\mathrm{Eu}^{3+}$ ions in high symmetry sites, whereas the broad luminescence spectrum and shorter luminescence decay lifetime reflect the glassy environment [23]. By comparison, the luminescence spectra recorded under $394 \mathrm{~nm}$ excitation (the ${ }^{7} \mathrm{D}_{0} \rightarrow{ }^{5} \mathrm{~F}_{2}$ transition) shows Stark splitting and longer decay time characteristic to the crystalline environment [23]. A similar approach was applied to the $\mathrm{Eu}^{3+}$-doped $\mathrm{SiO}_{2}-$ $\mathrm{BaF}_{2}$ glass ceramic (prepared in ref. [8]) and the spectra showed structured luminescence spectra for both excitation wavelengths but different red to green visible emissions ratios (Figure 5). The spectra are consistent with dominant incorporation of the $\mathrm{Eu}^{3+}$ ions within the $\mathrm{BaF}_{2}$ nanocrystals [8], exhibiting two different crystalline sites with higher and lower local symmetry.

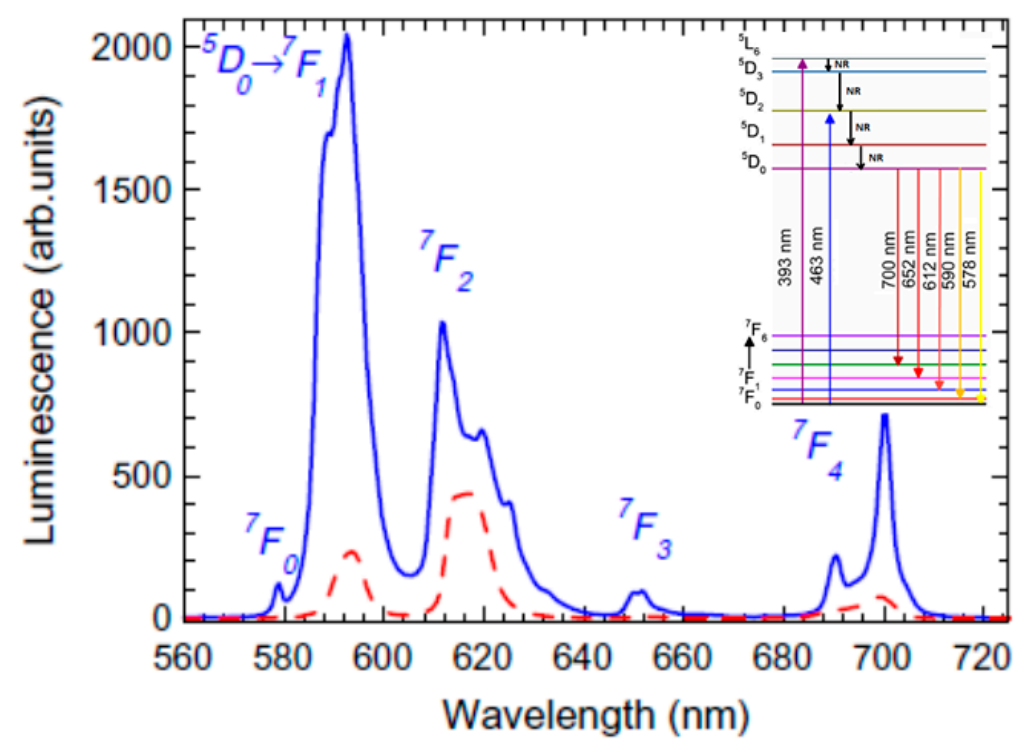

Figure 4. Photoluminescence spectra recorded on $\mathrm{Eu}^{3+}$-doped xerogel (dotted curve) and glass ceramic (solid curve) using $394 \mathrm{~nm}$ excitation wavelength (modified from reference [19]); the inset shows the $\mathrm{Eu}^{3+}$ energy levels diagram.

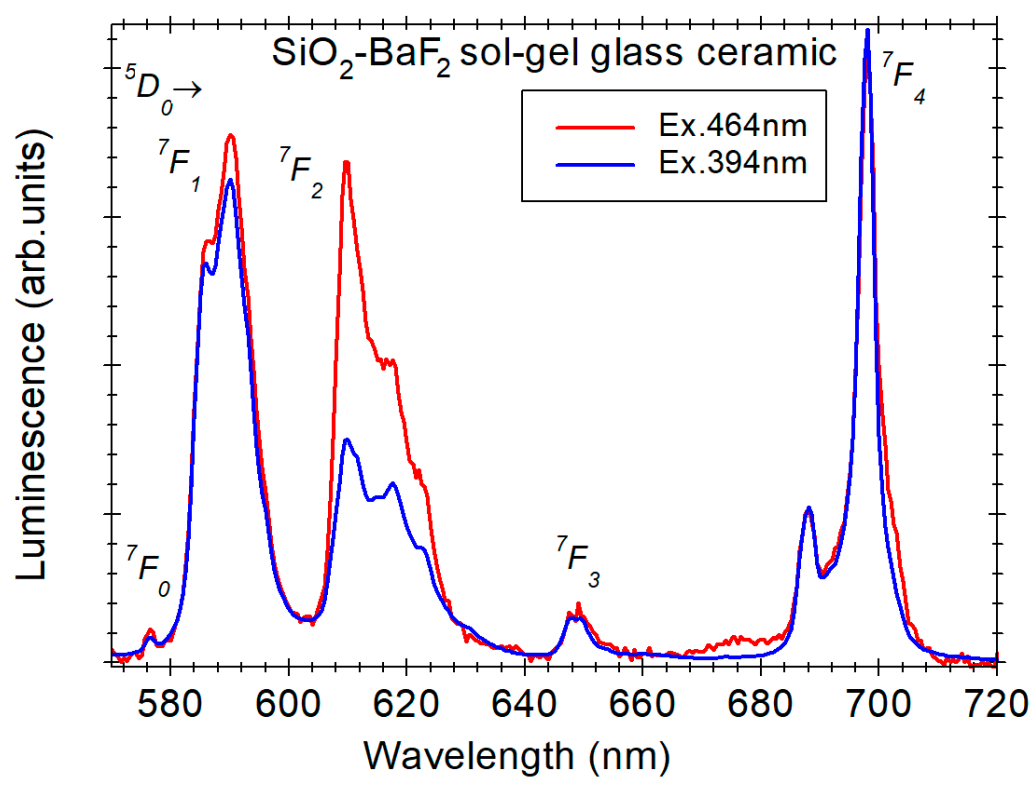

Figure 5. Photoluminescence spectra of Eu (1\%)-doped $95 \mathrm{SiO}_{2}-5 \mathrm{BaF}_{2}$ nano-glass ceramic (prepared in ref. [8]) recorded under 394 and $464 \mathrm{~nm}$ excitation. 
A special case is represented by the up-conversion luminescence (UC) shown by the rare-earth ions (or ion pairs) that is an anti-Stokes luminescence process where synergistic effects of light excitation and mutual interactions between ions produce higher energy emission photons [31]. For rare-earth doped materials, the UC mechanism is based on the large absorption cross-section in the NIR region around $1000 \mathrm{~nm}$ of $\mathrm{Yb}^{3+}$ and a very efficient energy transfer (ET) to one of the $\mathrm{Er}^{3+} / \mathrm{Ho}^{3+}$ or $\mathrm{Tm}^{3+}$ ions. The absorption of infrared light photons by the $\mathrm{Yb}^{3+}$ ions $\left({ }^{2} F_{7 / 2} \rightarrow{ }^{2} F_{5 / 2}\right.$ transition) is followed by a two-step energy transfer process to neighboring $\mathrm{Er}^{3+}$ ions with their characteristic green $\left(\left({ }^{2} \mathrm{H}_{11 / 2}\right.\right.$, $\left.\left.{ }^{4} S_{3 / 2}\right) \rightarrow{ }^{4} I_{15 / 2}\right)$ and red $\left({ }^{4} F_{9 / 2} \rightarrow{ }^{4} I_{15 / 2}\right)$ luminescent emissions (see Figure 6).
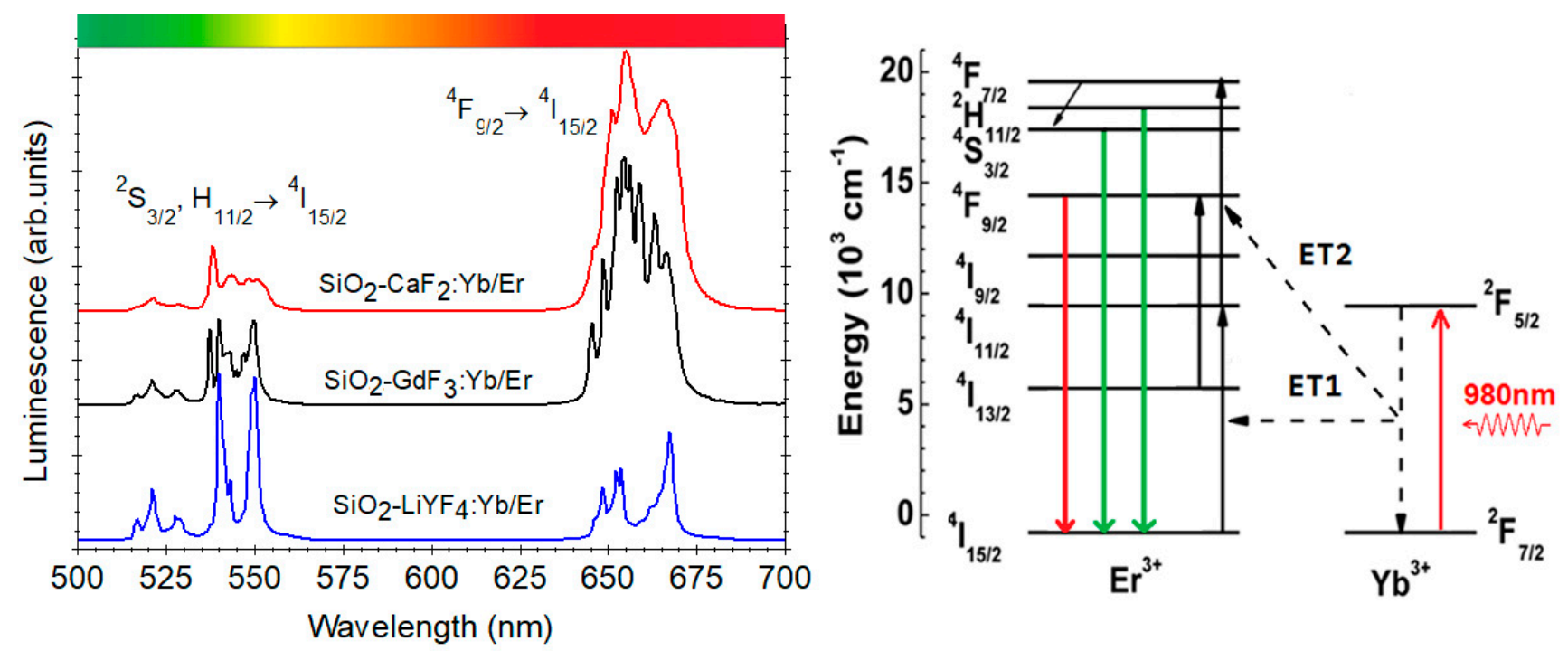

Figure 6. The green $\left({ }^{2} \mathrm{H}_{11 / 2},{ }^{4} \mathrm{~S}_{3 / 2} \rightarrow{ }^{4} \mathrm{I}_{15 / 2}\right)$ and red $\left({ }^{4} \mathrm{~F}_{9 / 2} \rightarrow{ }^{4} \mathrm{I}_{15 / 2}\right)$ Er ${ }^{3+}$ up-conversion luminescences excited at $980 \mathrm{~nm}$ in various $\mathrm{Yb}^{3+} / \mathrm{Er}^{3+}$-doped oxyfluoride glass ceramics [32] and the energy level schemes of $\mathrm{Yb}^{3+}$ and $\mathrm{Er}^{3+}$ with the main energy transfer processes.

Nanocrystalline phase formation has a great effect on the optical response to ionizing radiation, and this can be characterized by using thermoluminescence measurement technique. Thermoluminescence (TL) represents the light emission by a solid sample during controlled heating after irradiation by ionizing radiation such as UV light, X-rays, gammarays, etc. [33] and it has proved to be a useful and sensitive tool for the study of radiation effects in various materials. According to the basic model, charge carriers (electrons and holes) produced by irradiation (stage a) are trapped in local energy levels $T r$, (stage b), such as vacancies, interstitials, or impurities within the band gap; during the heating (stage c), they are thermally released and recombine at the recombination centers $R$ giving rise to TL [33]; the thermal activation energy is E. In particular, TL has proved an effective tool for the study of rare-earth induced levels in material and their behavior as electron or hole trap [35-37].

The TL properties of $\mathrm{Eu}^{3+}$-doped materials are due to the thermal release of the electrons from deep $\mathrm{Eu}^{3+}$-related traps followed by the recombination with the hole traps, resulting in the emission of light. TL properties were used to monitor the densification of $\mathrm{Eu}^{3+}$ doped $\mathrm{SiO}_{2}-\mathrm{BaF}_{2}$ dried xerogel prepared in ref. [8] to the glass ceramic (Figure 7-right). The investigations evidenced two glow peaks at 309 and $350{ }^{\circ} \mathrm{C}$ in the xerogel and a single dominant one at $370{ }^{\circ} \mathrm{C}$ in the glass ceramic, different from the glow peak observed in the $\mathrm{Eu}^{3+}$-silica glass at $400{ }^{\circ} \mathrm{C}$ [38]. This change was associated with structural changes during the ageing process of the gel and glass crystallization (Figure 7-right). 

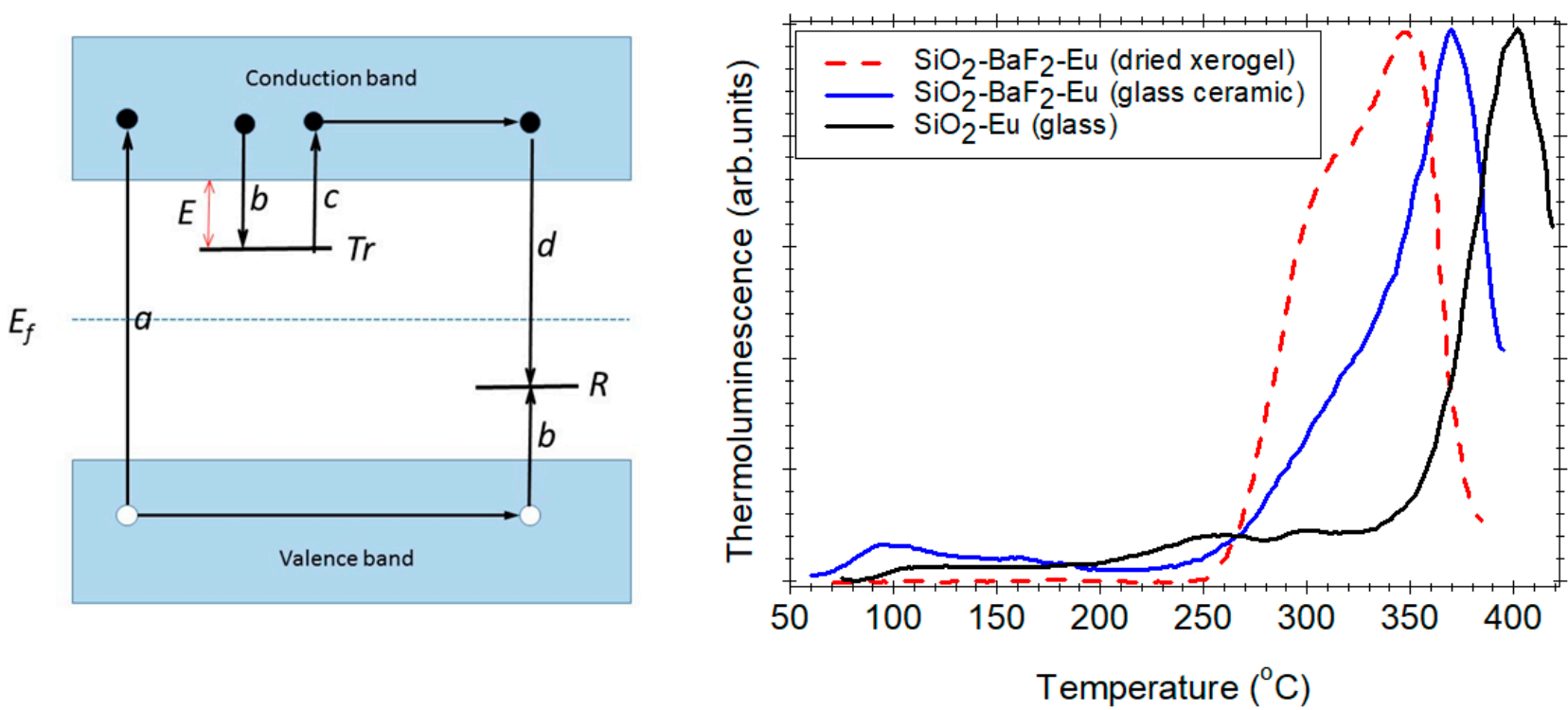

Figure 7. Thermoluminescence mechanism (left) (reproduced from reference [34]); and normalized glow curves recorded after $\mathrm{X}$-ray irradiation at room temperature of $\mathrm{Eu}^{3+}$ doped $\mathrm{SiO}_{2}-\mathrm{BaF}_{2}$ dried xerogel and $\mathrm{Eu}^{3+}$ doped glass ceramic (prepared in ref. [8]) (right).

\section{Oxyfluoride Glass Ceramic}

In the following sections, we present the most relevant results about the optical properties (mainly photo- and up-conversion luminescence properties) for $\mathrm{RE}^{3+}$ doped oxy-fluoride glass ceramics, depending on the nature of the nanocrystalline phase.

\section{1. $\mathrm{SiO}_{2}-\mathrm{MeF}_{2}$ Oxyfluoride Glass ceramic (with $\mathrm{Me}=\mathrm{Mg}, \mathrm{Ca}, \mathrm{Sr}, \mathrm{Ba}, \mathrm{Pb}$ )}

Alkali-earth fluorides are well-known optical materials with various applications for radiation detection (as scintillators and for thermoluminescence dosimetry) or as laser media due to excellent optical properties such as high transmittance from ultraviolet to mid infrared spectral range and easy incorporation of $\mathrm{RE}^{3+}$-ions.

\subsection{1. $\mathrm{SiO}_{2}-\mathrm{CaF}_{2}$ Oxyfluoride Glass Ceramic}

The first report on $1 \mathrm{~mol} \% \mathrm{ErF}_{3}$-doped $\mathrm{SiO}_{2}-\mathrm{CaF}_{2}$ glass ceramic was by Zhou et al. [39] - the precipitation of $\mathrm{CaF}_{2}$ crystals of about $20 \mathrm{~nm}$ size, homogeneously distributed in the amorphous $\mathrm{SiO}_{2}$ matrix, is accompanied by the $\mathrm{Er}^{3+}$ related red $\left({ }^{4} F_{9 / 2} \rightarrow{ }^{4} I_{15 / 2}\right)$ up-conversion luminescence. Further and deeper investigations on the UC luminescence properties of the $\mathrm{Yb} / \mathrm{Er}$ doped $\mathrm{SiO}_{2}-\mathrm{CaF}_{2}$ glass ceramic and the mechanism involved were conducted by Georgescu et al. (2013) [40]. The green $\left(\left({ }^{2} H_{11 / 2},{ }^{4} S_{3 / 2}\right) \rightarrow{ }^{4} I_{15 / 2}\right)$ and red $\left({ }^{4} F_{9 / 2} \rightarrow{ }^{4} I_{15 / 2}\right)$ up conversion luminescences (Figure 6) are accompanied by weaker blue-UV luminescences at $380 \mathrm{~nm}\left({ }^{4} G_{11 / 2} \rightarrow{ }^{4} I_{15 / 2}\right)$ and $405 \mathrm{~nm}\left({ }^{2} H_{9 / 2} \rightarrow{ }^{4} I_{15 / 2}\right)$ assigned to the $\mathrm{Er}^{3+}$ ions deexcitation from higher energy levels. The analysis of the upconversion emissions indicated a two-photon processes for the red-green luminescence while the blue-UV luminescences is ascribed to three-photon processes. Their internal quantum efficiencies- $0.88 \%$ (blue), $0.44 \%$ (green), and $10.6 \%$ (red)-were estimated from the fluorescence lifetimes of the blue, green, and red luminescences.

The $\mathrm{Eu}^{3+}$ ions environment in the silica glass and $\mathrm{SiO}_{2}-\mathrm{CaF}_{2}$ glass ceramic was investigated by using phonon side bands (PSB) measurements [15,17] (Figure 8). The local structures around $\mathrm{Eu}^{3+}$ ions give rise to local vibration modes that can be observed as vibronic lines associated to excitation peaks, i.e., PSB. The PSB peaks were assigned to the vibrations of the $\mathrm{SiO}_{4}$ tetrahedra units of the glass network (above $\cong 500 \mathrm{~cm}^{-1}$ ) and $\mathrm{Ca}-\mathrm{F}$ bonds vibrations in the precipitated $\mathrm{CaF}_{2}$ nanocrystalline phase (below $\cong 500 \mathrm{~cm}^{-1}$ ). The presence of $\mathrm{Si}-\mathrm{O}, \mathrm{Eu}-\mathrm{O}$, and $\mathrm{Eu}-\mathrm{F}$ bonds is consistent with the $\mathrm{Eu}^{3+}$ ions partition in 
both silica glass matrix and $\mathrm{CaF}_{2}$ nanocrystaline phase, i.e., in the non-centrosymmetric sites of the $\mathrm{CaF}_{2}$ nanocrystals structure [15].

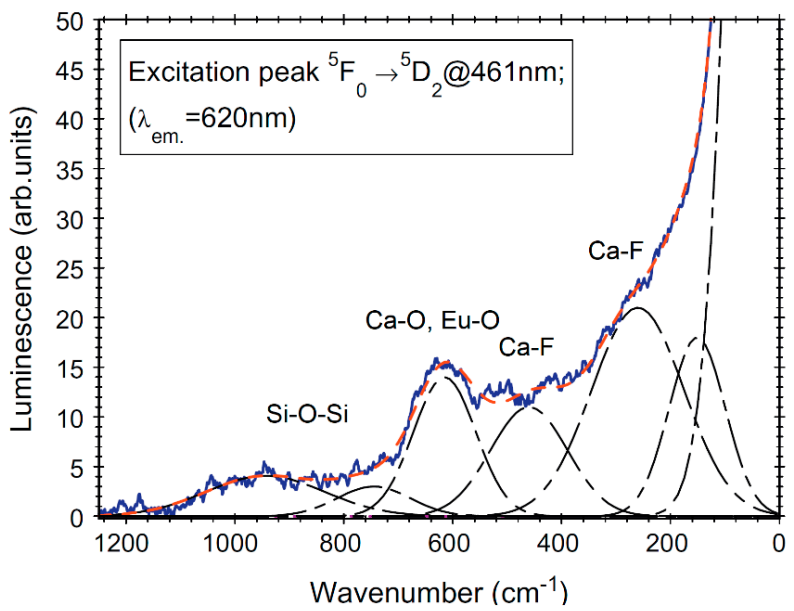

Figure 8. The PSB spectrum associated to the ${ }^{5} \mathrm{~F}_{0} \rightarrow{ }^{5} \mathrm{D}_{2}$ transition of $\mathrm{Eu}^{3+}$-ion (at $461 \mathrm{~nm}$ ), recorded in glass-ceramic (solid curve) and the fit with Gaussian-type curves (dashed curves); the abscissa is taken as the energy shift from the pure electronic transition (PET) peak ${ }^{5} \mathrm{~F}_{0} \rightarrow{ }^{5} \mathrm{D}_{2}$ at $461 \mathrm{~nm}$. (Modified from reference [15].)

New evidence on the $\mathrm{Eu}^{3+}$ ions partition was provided by the thermoluminescence measurements. Thermoluminescence investigations of $\mathrm{SiO}_{2}-\mathrm{CaF}_{2}$ glass ceramic revealed a glow peak at $370{ }^{\circ} \mathrm{C}$, assigned to the recombination of the electrons released from the $\mathrm{Eu}^{3+}$-electron traps in the $\mathrm{CaF}_{2}$ nanocrystals, which is shifted from the peak observed in the $\mathrm{Eu}^{3+}$-doped silica glass at $400{ }^{\circ} \mathrm{C}$ [38]; the broadening of the glow peaks is consistent with multiple $\mathrm{Eu}^{3+}$-ion sites.

\subsection{2. $\mathrm{SiO}_{2}-\mathrm{SrF}_{2}$ Oxyfluoride Glass Ceramic}

Luminescence properties of $\mathrm{Eu}^{3+} / \mathrm{Tb}^{3+}$ co-doped $\mathrm{SiO}_{2}-\mathrm{SrF}_{2}$ glass ceramics have been studied and showed cross-relaxation in materials with $\mathrm{Tb}^{3+}$ dopant as well as energy transfer from $\mathrm{Tb}^{3+}$ to $\mathrm{Eu}^{3+}$. White luminescence can be achieved by combining blue emission of $\mathrm{SiO}_{2}$, green light emitted by $\mathrm{Tb}^{3+}$ and red one by $\mathrm{Eu}^{3+}$, resulting in a white phosphor-like behavior [41] (Figure 9).

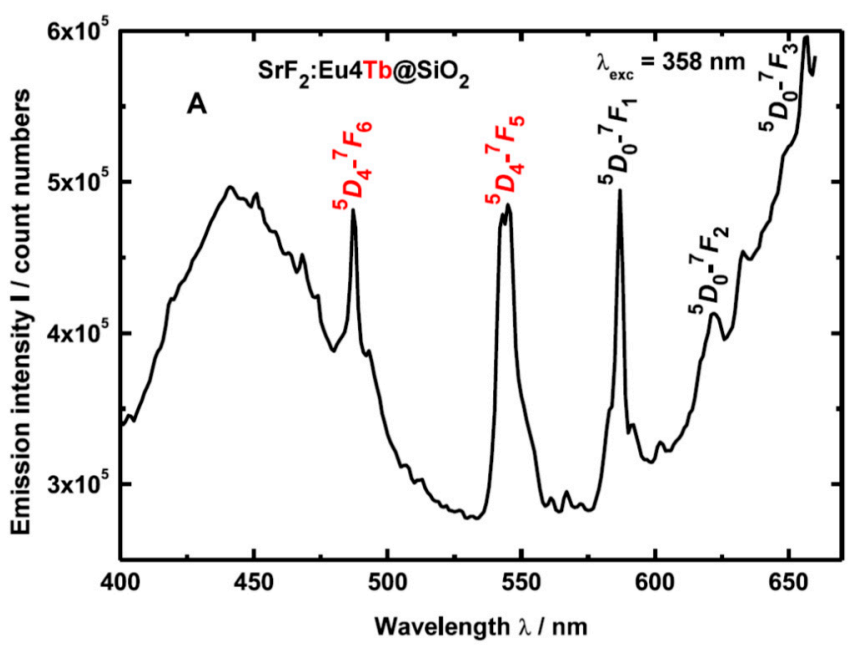

Figure 9. Photoluminescence spectra recorded on $\mathrm{SrF}_{2}: \mathrm{Eu} / \mathrm{Tb}_{\mathrm{SiO}}$ glass ceramics after under $368 \mathrm{~nm}$ excitation wavelength; blue broad emission of $\mathrm{SiO}_{2}$ is accompanied by the green light peaks of $\mathrm{Tb}^{3+}$ and red light peaks of $\mathrm{Eu}^{3+}$ (reproduced from reference [41]). 
Up-conversion luminescence spectra of $\mathrm{Er}^{3+}$-doped $\mathrm{SiO}_{2}-\mathrm{SrF}_{2}$ oxyfluoride glass ceramic showed resolved Stark components of ${ }^{4} \mathrm{I}_{13 / 2}$ band in the glass ceramics compared to the xerogel, assigned to the change of the environment around $\mathrm{Er}^{3+}$ from the glass to nanocrystals [42]. Moreover, the introduction of $\mathrm{Al}^{3+}$ to the $\mathrm{SiO}_{2}$ network caused an improvement of the optical properties: better transparency in the UV region due to lower pore content and intense visible UC luminescence as compared to the one with only $\mathrm{SiO}_{2}$ [42].

\subsection{3. $\mathrm{SiO}_{2}-\mathrm{BaF}_{2}$ Oxyfluoride Glass Ceramic}

Transparent glass ceramics containing $\mathrm{Er}^{3+}$-doped $\mathrm{BaF}_{2}$ nano-crystals doped were prepared by sol-gel route and upconversion luminescence was assigned to the $\mathrm{Er}^{3+}$-ions incorporated within the $\mathrm{BaF}_{2}$ nanocrystals of about 2-15 nm size [43]. Further investigations of $\mathrm{RE}^{3+}$-doped $\mathrm{SiO}_{2}-\mathrm{BaF}_{2}$ glass ceramic $(\mathrm{RE}=\mathrm{Ho}, \mathrm{Dy}, \mathrm{Eu}, \mathrm{Sm})$ showed that in the glass ceramic material, a large fraction of $\mathrm{RE}^{3+}$ optically active ions is partitioned into $\mathrm{BaF}_{2}$ nanocrystals of about $10 \mathrm{~nm}$ size $[8,19]$. The $\mathrm{Eu}^{3+}$-luminescence signal enhancement is accompanied by an increase of luminescence lifetime, from $0.27 \mathrm{~ms}$ in dried xerogel to $4.7 \mathrm{~ms}$ in the glass ceramic [8].

Thermoluminescence measurements recorded after X-ray irradiation of $\mathrm{RE}^{3+}$-doped $\mathrm{SiO}_{2}-\mathrm{BaF}_{2}$ glass ceramic indicated that new deep trap levels are introduced by the $\mathrm{RE}^{3+}$ doping: $\cong 140{ }^{\circ} \mathrm{C}$ (for $\left.\mathrm{Ho}^{3+}, \mathrm{Dy}^{3+}\right), 340{ }^{\circ} \mathrm{C}\left(\right.$ for $\mathrm{Sm}^{3+}$ ), and $370{ }^{\circ} \mathrm{C}\left(\right.$ for $\mathrm{Eu}^{3+}$ ); in undoped glass ceramic, the TL peak was observed at $383{ }^{\circ} \mathrm{C}$. The glow peaks were assigned to the recombination of $\mathrm{RE}^{3+}$-related electron traps located mainly inside the $\mathrm{BaF}_{2}$ nanocrystals (Figure 10). Within the series, the trivalent lanthanide ions act as increasingly deeper electron trapping centers [34-38] and this can be observed as glow peaks shift in the temperature scale [36]. The glow peaks energy within the energy levels model proposed for the crystals might be influenced by the nanosize-related effects on the band gap energy.
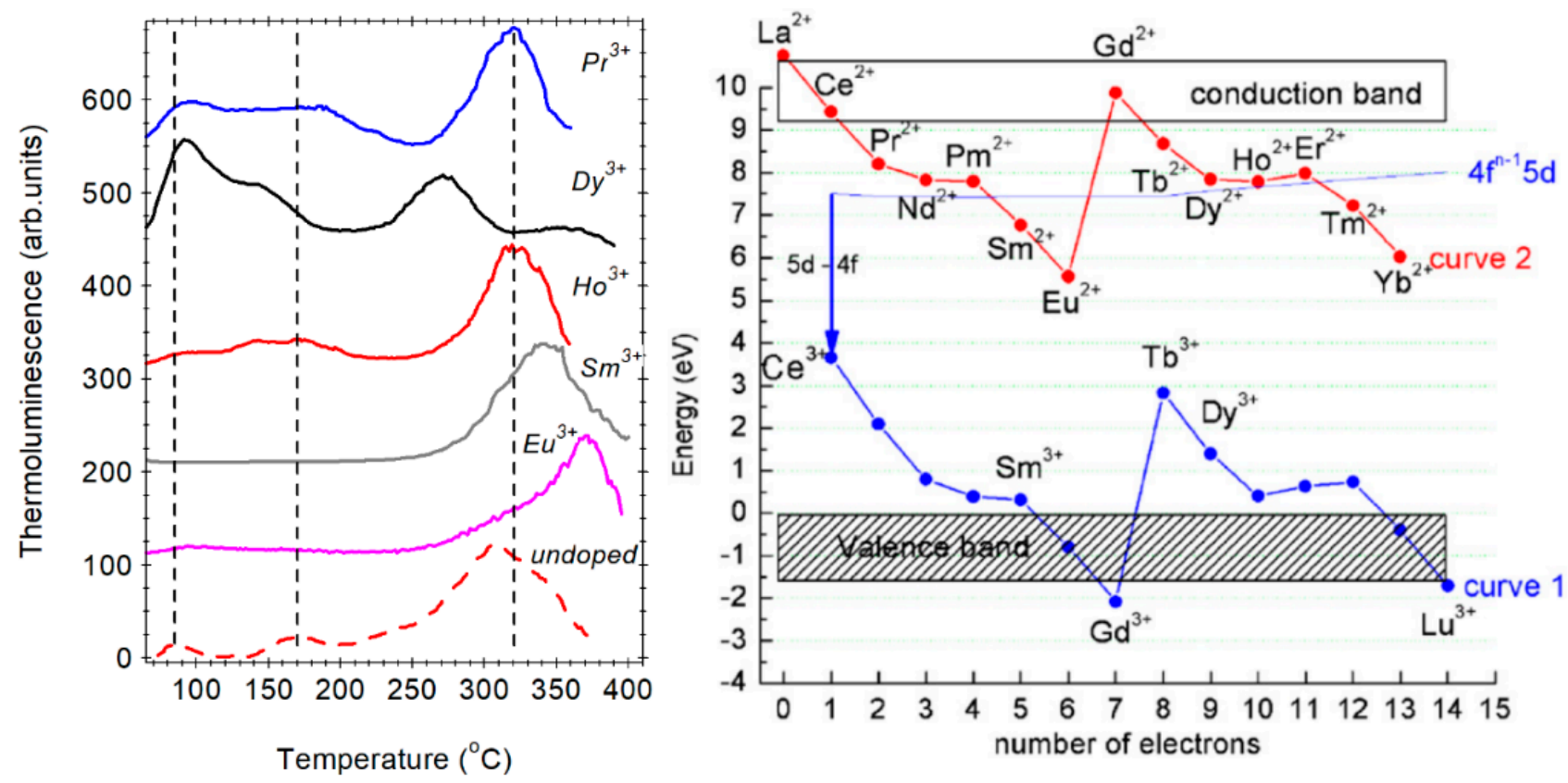

Figure 10. TL curves recorded on undoped (dotted line) and $\mathrm{RE}^{3+}$-doped glass ceramics (solid lines) after $\mathrm{X}$-ray irradiation at room temperature (reproduced from reference [44]); the energy levels scheme of lanthanides in $\mathrm{YPO}_{4}$ (reproduced from reference [34]).

\subsection{4. $\mathrm{SiO}_{2}-\mathrm{PbF}_{2}$ Oxyfluoride Glass Ceramic}

The first study on $\mathrm{Er}^{3+}$-doped $\mathrm{SiO}_{2}-\mathrm{PbF}_{2}$ oxyfluoride glass ceramic made by Luo et al. [44] assigned the crystallization of $\beta-\mathrm{PbF}_{2}$ phase to a diffusion-controlled process of three-dimensional growth with decreasing nucleation. It was assumed that $\mathrm{Er}^{3+}$-ions 
segregated at the surface of the crystallites and hindered the growth of $\beta-\mathrm{PbF}_{2}$, thus postponing the crystallization. Later on, the studies were extended to crystallization behavior, structural investigation, and optical properties of other rare earth doped $\mathrm{SiO}_{2}-$ $\mathrm{PbF}_{2}$ oxyfluoride glass ceramics.

Glass ceramic containing $\mathrm{Eu}^{3+} / \mathrm{Tb}^{3+}$ singly-doped $\beta-\mathrm{PbF}_{2}$ nanocrystals containing nanocrystals of around 10-15 nm size embedded in silica amorphous hosts were synthesized and their optical properties studied $[12,45,46]$. Luminescence decay kinetics showed non-exponential decays with shorter and longer luminescence lifetimes: $\left(\mathrm{Eu}^{3+}\right.$ : $\left.\tau_{1}\left({ }^{5} \mathrm{D}_{0}\right)=0.90 \mathrm{~ms}, \tau_{2}\left({ }^{5} \mathrm{D}_{0}\right)=5.15 \mathrm{~ms} ; \mathrm{Tb}^{3+}: \tau_{1}\left({ }^{5} \mathrm{D}_{4}\right)=0.48 \mathrm{~ms}, \tau_{2}\left({ }^{5} \mathrm{D}_{4}\right)=4.01 \mathrm{~ms}\right)$ corresponding to two different surroundings around $\mathrm{Eu}^{3+}$ and $\mathrm{Tb}^{3+}$ dopants, silica glassy hosts, and $\beta-\mathrm{PbF}_{2}$ nanocrystals. The analysis of the luminescence intensity ratios as well as double-exponential character of luminescence decay curves clearly indicated the incorporation of $\mathrm{RE}^{3+}$ dopant ions into formed low phonon $\beta-\mathrm{PbF}_{2}$ nanocrystalline phase.

The up-conversions properties of transparent $0.3 \mathrm{Yb}^{3+} / 0.1 \mathrm{Er}^{3+}(\mathrm{mol} \%)$ co-doped $90 \mathrm{SiO}_{2}-$ $10 \mathrm{PbF}_{2}$ oxyfluoride glass-ceramics were extensively studied by J. del-Castillo et al. [47,48]. $X$-ray diffraction and electron microscopy analysis showed the precipitation of cubic $\beta-\mathrm{PbF}_{2}$ nanocrystals varying from 5 to $25 \mathrm{~nm}$ depending on heat treatment conditions at low temperatures, i.e., $300-400{ }^{\circ} \mathrm{C}$. The up-conversion luminescence spectra showed green $\left(\left({ }^{2} H_{11 / 2},{ }^{4} S_{3 / 2}\right) \rightarrow{ }^{4} I_{15 / 2}\right)$ and $\mathrm{red}\left({ }^{4} F_{9 / 2} \rightarrow{ }^{4} I_{15 / 2}\right)$ luminescence at $520-540$ and $660 \mathrm{~nm}$, respectively, accompanied by weaker blue luminescence at $410 \mathrm{~nm}\left({ }^{2} H_{9 / 2} \rightarrow{ }^{4} I_{15 / 2}\right)$ all assigned to the $\mathrm{Er}^{3+}$ transitions; the Stark splitting is consistent with the ions incorporation within the nanocrystals that assure an efficient energy transfer between ions (Figure 11).

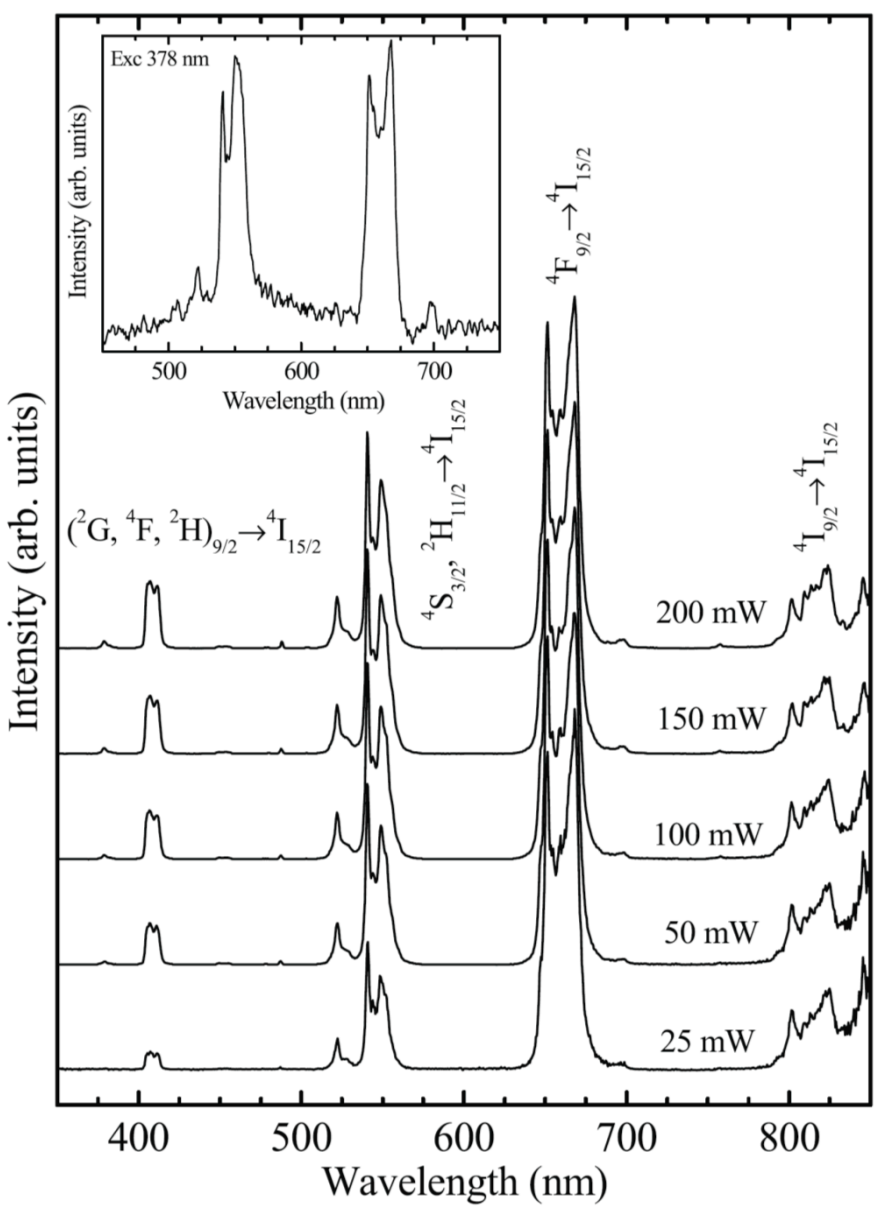

Figure 11. Up-conversion emission spectra of $\mathrm{Er}^{3+}$-doped $\mathrm{SiO}_{2}-\mathrm{PbF}_{2}$ glass ceramic under $980 \mathrm{~nm} \mathrm{IR}$ light pumping at different powers; the inset shows emission spectrum excited at $378 \mathrm{~nm}$ (reproduced from reference [47]). 
The analysis of the dynamics of the up-conversion emissions indicated that distinct energy transfer excitation pathways are responsible for populating the luminescent levels: two and three photon processes for red-visible emission at 520-540 nm and $660 \mathrm{~nm}$, and blue emission at $410 \mathrm{~nm}$, respectively. Moreover, white up-conversion luminescence was obtained by combining the blue and red upconversion emissions band of $\mathrm{Tm}^{3+}$ with the upconversion green emission bands of $\mathrm{Er}^{3+}$ or $\mathrm{Ho}^{3+}$ and by using different pump powers and ratios between co-dopants [48].

\section{2. $\mathrm{SiO}_{2}-\mathrm{MeF}_{3}$ Oxyfluoride Glass Ceramic (with $\mathrm{Me}=\mathrm{La}, \mathrm{Y}, \mathrm{Gd}, \mathrm{Ce}$ )}

Rare-earth doped trifluorides and the corresponding oxyfluoride glass ceramics are attractive optical materials because of their wide band-gap, high solubility of rare-earth ions without additional charge compensation, and possible energy transfer (ET) processes to other co-dopant ions (for $\mathrm{Gd}^{3+}$ and $\mathrm{Ce}^{3+}$ ).

\subsection{1. $\mathrm{SiO}_{2}-\mathrm{LaF}_{3}$ Oxyfluoride Glass Ceramic}

The first studies on the glass ceramization investigations in the $\mathrm{SiO}_{2}-\mathrm{LaF}_{3}$ system revealed the importance of controlling the synthesis and heat treatment parameters [5-7]. Recent investigations on the crystallization process of $\mathrm{SiO}_{2}-\mathrm{LaF}_{3}$ glass-ceramics indicated a chemical reaction, followed by the fast precipitation of $\mathrm{LaF}_{3}$ crystals and not diffusioncontrolled nucleation and growing process, as in the melt-quenched glasses [10]. Structural and optical investigations of nano-structured $\mathrm{Eu}^{3+}$-doped $\mathrm{SiO}_{2}-\mathrm{LaF}_{3}$ transparent glassceramics calcinated at $800{ }^{\circ} \mathrm{C}$ [49] were used to investigate the $\mathrm{Eu}^{3+}$ ions partition in both glassy and crystalline phases. Site selective luminescence spectroscopy revealed the $393 \mathrm{~nm}$ excitation peak assigned to the $\mathrm{Eu}^{3+}$ ions in the silica glassy phase, whereas the $396 \mathrm{~nm}$ peak would correspond to $\mathrm{Eu}^{3+}$ ions partitioned into $\mathrm{LaF}_{3}$ nanocrystals (Figure 12). It is concluded that about half the $\mathrm{Eu}^{3+}$ ions are partitioned into fluoride nanocrystals, while the rest remains in the glassy phase.

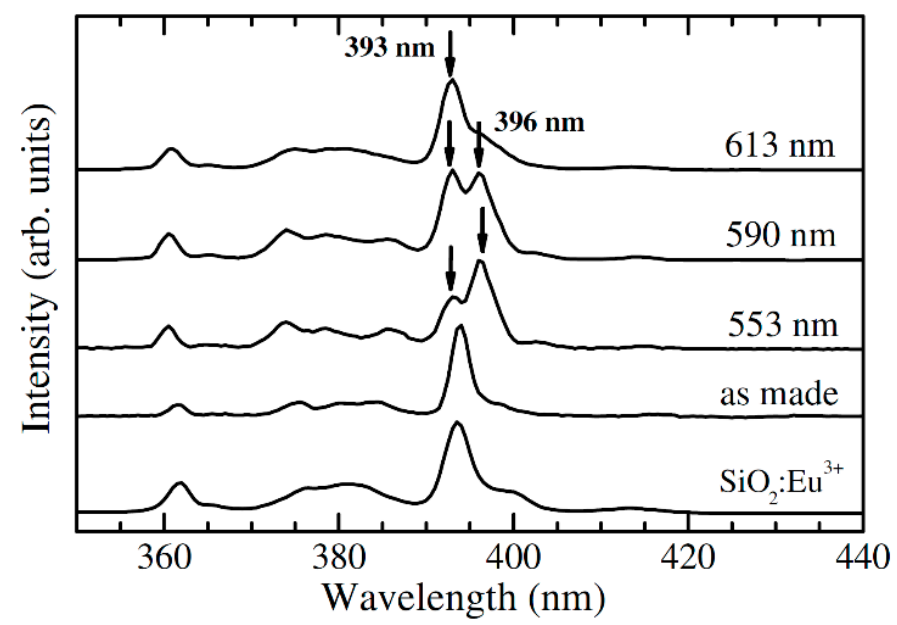

Figure 12. Excitation spectra of $\mathrm{Eu}^{3+}$-doped $\mathrm{LaF}_{3}-\mathrm{SiO}_{2}$ glass ceramics recorded at indicated wavelengths; the spectra of $89.9 \mathrm{SiO}_{2}-10 \mathrm{LaF}_{3}-0.1 \mathrm{EuF}_{3}$ glassy sample and $\mathrm{SiO}_{2}: \mathrm{Eu}^{3+}$ sol-gel glass detected at $590 \mathrm{~nm}$ are also included (reproduced from reference [49]).

The liquid sol transformation to xerogel and then Eu-doped $\mathrm{SiO}_{2}-\mathrm{LaF}_{3}$ glass ceramic was investigated by using photoluminescence spectroscopy [20,50,51]. The Eu ${ }^{3+}$ luminescence spectra and luminescence decay analysis showing a double-exponential character (with $\tau_{1}\left({ }^{5} \mathrm{D}_{0}\right)=2.07 \mathrm{~ms}, \tau_{2}\left({ }^{5} \mathrm{D}_{0}\right)=8.07 \mathrm{~ms}$ and $\tau_{1}\left({ }^{5} \mathrm{D}_{0}\right)=0.79 \mathrm{~ms}, \tau_{2}\left({ }^{5} \mathrm{D}_{0}\right)=9.76 \mathrm{~ms}$ for powders and glass ceramics, respectively) indicated the incorporation of optically active $\mathrm{Eu}^{3+}$ ions from amorphous silica framework into the low phonon energy $\mathrm{LaF}_{3}$ nanocrystalline phase. Moreover, the intensity ratio between the two visible emissions $\left({ }^{5} \mathrm{D}_{0}-{ }^{7} \mathrm{~F}_{2} /{ }^{5} \mathrm{D}_{0}-{ }^{7} \mathrm{~F}_{1}\right)$ 
was used to analyze the local symmetry around $\mathrm{Eu}^{3+}$ ions: the observation of the ratio value decrease is consistent with the ions' incorporation within the $\mathrm{LaF}_{3}$ nanocrystals.

Up-conversion luminescence properties and the mechanism were investigated in $95 \mathrm{SiO}_{2}-5 \mathrm{LaF}_{3}: 0.1 \mathrm{Er}^{3+}$ glass ceramic [52] (Figure 13) and $\mathrm{Yb}-\mathrm{Er}$ or $\mathrm{Yb}-\mathrm{Ho}, \mathrm{Yb}-\mathrm{Tm}$ doped $\mathrm{SiO}_{2}-\mathrm{LaF}_{3}$ glass ceramics [53-56]. Segregation of $\mathrm{LaF}_{3}$ nanocrystals in the matrix was confirmed by $\mathrm{X}$-ray diffraction and upconversion emissions associated with the $\mathrm{Er}, \mathrm{Ho}$, and Tm ions in the nanocrystals were observed under $980 \mathrm{~nm}$ IR light excitation. Color tuneability and white light generation were observed in triple $\mathrm{Yb}^{3+} / \mathrm{Ho}^{3+} / \mathrm{Tm}^{3+}$ co-doped $\mathrm{SiO}_{2}-\mathrm{LaF}_{3}$ nano glass ceramics [57].
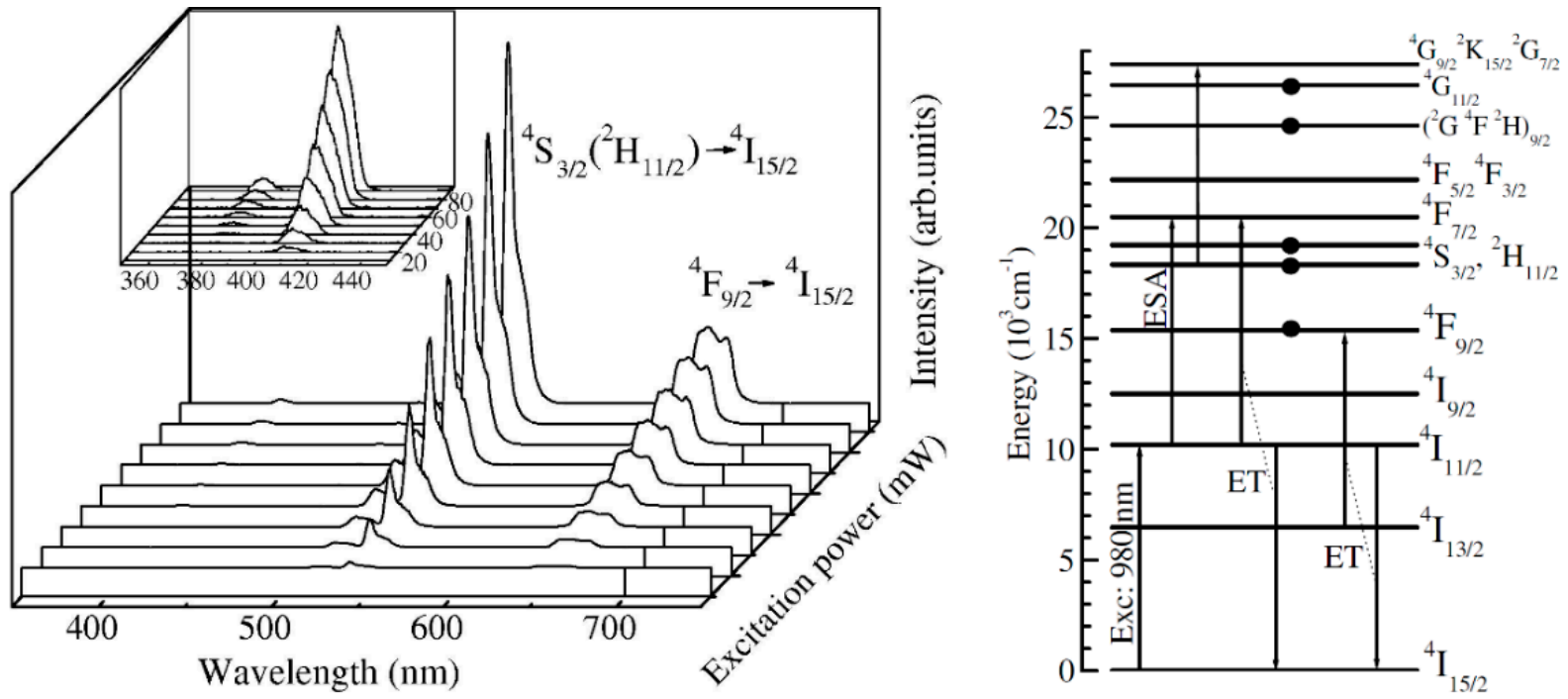

Figure 13. Up-conversion luminescence spectra of $95 \mathrm{SiO}_{2}-5 \mathrm{LaF}_{3}: 0.1 \mathrm{Er}^{3+}$ glass ceramics recorded at room temperature under $980 \mathrm{~nm}$ IR light pumping with different pumping powers from 10 to $90 \mathrm{~mW}$ (left) and the energy level schemes of $\mathrm{Er}^{3+}$ with the main energy transfer processes (right); reproduced from reference [52].

\subsection{2. $\mathrm{SiO}_{2}-\mathrm{YF}_{3}$ Oxyfluoride Glass Ceramic}

Structural and morphological investigations of $\mathrm{Eu}^{3+}$-doped $\mathrm{SiO}_{2}-\mathrm{YF}_{3}$ sol-gel nanoglass ceramics have indicated the precipitation of $\mathrm{YF}_{3}$ nanocrystals with an average diameter of about $15 \mathrm{~nm}$ [57]. The reducing of the $\left({ }^{5} \mathrm{D}_{0}-{ }^{7} \mathrm{~F}_{2} /{ }^{5} \mathrm{D}_{0}-{ }^{7} \mathrm{~F}_{1}\right)$ intensity ratio value from 2.82 to 0.66 as well as bi-exponential character of decay curves (with shorter and longer lifetimes, 0.86 and $1.14 \mathrm{~ms}$ ) was assigned to the incorporation of $\mathrm{Eu}^{3+}$ ions in both glassy and $\mathrm{YF}_{3}$ nanocrystalline phases, respectively.

An exhaustive analysis of the luminescence properties of $\left(\mathrm{Eu}^{3+}, \mathrm{Sm}^{3+}\right)$ doped $\mathrm{SiO}_{2}-\mathrm{YF}_{3}$ structured glass-ceramic containing nanocrystals of around $11 \mathrm{~nm}$ was performed by A. Carlos Yanes et al. [23]. Selective excitation wavelengths and luminescence decay measurements allowed discerning between ions residing in precipitated $\mathrm{YF}_{3}$ nanocrystals and those remaining in a glassy environment; a large fraction of optically active ions is efficiently partitioned into nanocrystals. Moreover, for $\mathrm{Yb}^{3+}-\mathrm{Tm}^{3+}$ co-doped samples, bright and efficient up-conversion was observed, as well as very intense high-energy emissions in the UV range strongly dependent on the $\mathrm{Yb}^{3+}$ doping level opening the way to developing short-wavelength solid-state lasers for various photonic related applications [23]. The investigations of $\mathrm{Tb}^{3+} / \mathrm{Eu}^{3+}$ co-doped sol-gel glass ceramic materials containing $\mathrm{MF}_{3}$ $(\mathrm{M}=\mathrm{Y}, \mathrm{La})$ nanocrystals showed $\mathrm{Tb}^{3+} \rightarrow \mathrm{Eu}^{3+}$ energy transfer process (ET) accompanied by multicolor emission due to the visible $4 \mathrm{f}^{\mathrm{n}}-4 \mathrm{f}^{\mathrm{n}}$ transitions of $\mathrm{Tb}^{3+}$ and $\mathrm{Eu}^{3+}$ ions [58].

\subsection{3. $\mathrm{SiO}_{2}-\mathrm{MeF}_{3}$ Oxyfluoride Glass Ceramic (with $\mathrm{Me}=\mathrm{Gd}, \mathrm{Ce}$ )}

Oxyfluoride glass ceramics containing $\mathrm{GdF}_{3}$ or $\mathrm{CeF}_{3}$ nanocrystals dispersed in the $\mathrm{SiO}_{2}$ matrix have been obtained and the optical properties of $\mathrm{RE}^{3+}$-ions studied. The energy 
levels overlap between the ${ }^{6} \mathrm{P}_{\mathrm{J}}$ states of $\mathrm{Gd}^{3+}$ and the UV-excited states of RE-ions promote an efficient energy transfer from $\mathrm{Gd}^{3+}$ to the $\mathrm{RE}^{3+}$ ions resulting in their characteristic photoluminescence. Crystalline phases analysis of $\mathrm{RE}^{3+}$-doped $\mathrm{SiO}_{2}-\mathrm{GdF}_{3}$ oxyfluoride glass ceramics has shown the precipitation of both hexagonal and orthorhombic $\mathrm{GdF}_{3}$ nanocrystals [59,60] or only orthorhombic one [61-63] in the silica matrix, depending on the synthesis path and the chemical composition of the system [50].

The luminescence spectra and luminescence decay measurements recorded on $\mathrm{Eu}^{3+} / \mathrm{Tb}^{3+}$ doped $\mathrm{SiO}_{2}-\mathrm{GdF}_{3}$ oxyfluoride glass ceramics indicate the incorporation of the $\mathrm{RE}^{3+}$ ions within the nanocrystalline phase and silica glass matrix (Figure 14). The energy transfer process from $\mathrm{Gd}^{3+}$ to $\mathrm{Eu}^{3+}$ or $\mathrm{Tb}^{3+}$ ions was evidenced by the excitation spectra and luminescence spectra recorded under $\mathrm{Gd}^{3+}$ ions excitation wavelength at $273 \mathrm{~nm}$ [63].

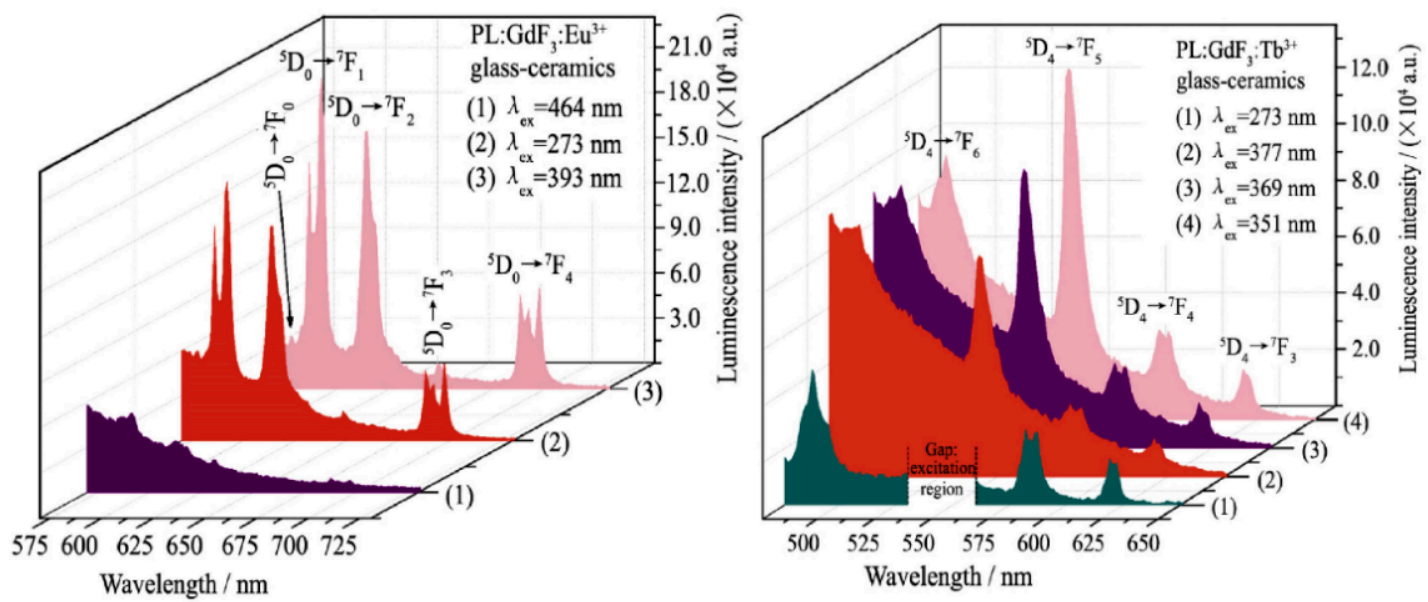

Figure 14. Photoluminescence spectra recorded in $\mathrm{Eu}^{3+}$ doped $\mathrm{SiO}_{2}-\mathrm{GdF}_{3}$ glass ceramic (left) and $\mathrm{Tb}^{3+} \mathrm{doped}_{\mathrm{SiO}}-\mathrm{GdF}_{3}$ glass ceramic excited at $\mathrm{Gd}^{3+}$ or $\mathrm{Eu}^{3+} / \mathrm{Tb}^{3+}$ excitation wavelength peaks (reproduced from reference [63]).

Recently we used Fujuhara's approach [5] for the synthesis of Eu-doped and $\mathrm{Yb} / \mathrm{Er}$ co-doped $\mathrm{SiO}_{2}-\mathrm{GdF}_{3}$ and $\mathrm{SiO}_{2}-\mathrm{LiGdF}_{4}[64,65]$ glass ceramics and the key role played by the nature of the RE-dopant ions and Li co-dopants ions in the stabilization of orthorhombic $\mathrm{GdF}_{3}$ phase: the nanocrystals size increase from $9 \mathrm{~nm}$ to $25 \mathrm{~nm}$ is accompanied by strong lattice distortion evidenced by XRD peaks shift towards higher angles [65] (Figure 15). Under $980 \mathrm{~nm}$ IR light pumping, we observed up-conversion luminescence signal assigned to the $\mathrm{Er}^{3+}$ ions (Figure 6), with more than one order of magnitude higher in Li co-doped glass ceramic.

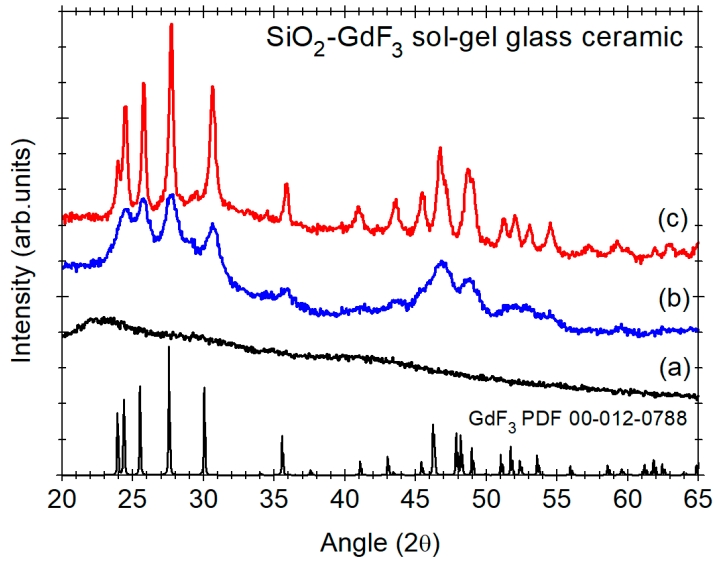

Figure 15. X-ray diffraction patterns of the $\mathrm{Yb} / \mathrm{Er}$ co-doped $\mathrm{SiO}_{2}-\mathrm{GdF}_{3}$ xerogel (curve a) and glass ceramics undoped (curve b) and $\mathrm{Li}\left(1 \%\right.$ ) co-doped (c) [65]; the PDF file of orthorhombic $\mathrm{GdF}_{3}$ is shown for comparison. 
For $\mathrm{RE}^{3+}$-doped $\mathrm{SiO}_{2}-\mathrm{CeF}_{3}$ sol-gel glass-ceramics with $\mathrm{RE}=\mathrm{Eu}, \mathrm{Sm}, \mathrm{Yb} / \mathrm{Er}$, structural and morphologic characterization has showed precipitation of the $\mathrm{CeF}_{3}$ nanocrystals [66]. The analysis of the intense red-orange emissions due to $\mathrm{Eu}^{3+}$ and $\mathrm{Sm}^{3+}$ transitions and the excitation spectra confirmed the partition of a large fraction of these ions into the precipitated $\mathrm{CeF}_{3}$ nanocrystals. A cross-relaxation process occurs between $\mathrm{Eu}^{3+}$ and $\mathrm{Ce}^{3+}$ ions and therefore the emissions from higher ${ }^{5} \mathrm{D}_{1}$ and ${ }^{5} \mathrm{D}_{0}$ energy levels are inhibited by the phonon-assisted energy transfer between the ions. In addition, in the $\mathrm{Yb} / \mathrm{Er}$ codoped samples, the presence of $\mathrm{Ce}^{3+}$ ions as a phonon-assisted cross-relaxation channel is responsible for a strong emission at $1.5 \mu \mathrm{m}$, which also leads to a drastic inhibition of the up-conversion emission.

\section{Thernary and More Complex Oxyfluoride Glass Ceramic}

The sol-gel route has been used to obtain other transparent glass ceramic compositions comprising thernary fluoride nanocrystalline Me1Me2F4 phases such as: $\mathrm{SiO}_{2}$ $\mathrm{NaYF}_{4}$ [67], $\mathrm{SiO}_{2}-\mathrm{NaLaF}_{4}$ [68], $\mathrm{SiO}_{2}-\mathrm{NaGdF}_{4}$ [69], $\mathrm{SiO}_{2}-\mathrm{KLaF}_{4}$ [70], $\mathrm{SiO}_{2}-\mathrm{KYF}_{4}$ [71], $\mathrm{SiO}_{2}-\mathrm{LiYF}_{4}[30,72,73]$ and their properties have been investigated. In these cases, the crystallization mechanism seems to be more complicated and the decomposition of metal trifluoroacetates is likely to be accompanied by some chemical reaction between metal and fluorine partners, followed by nanocrystalline phase precipitation within the glassy matrix. It was observed that the nature of the final precipitate crystalline phase is strongly dependent on the molar ratio between trivalent ion $(\mathrm{Y}, \mathrm{Gd}, \mathrm{La})$ and alkali metals

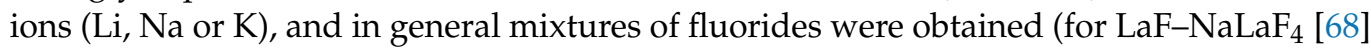
and $\mathrm{YF}_{3}-\mathrm{LiYF}_{4}[30,72,73]$ ) or different phase mixtures of the same compound (cubic and/or hexagonal $\mathrm{NaGdF}_{4}$ or $\mathrm{KLaF}_{4}$ nanocrystals $\left.[69,70]\right)$. Hence, an optimization of the initial composition and processing parameters (time and temperature) was required to obtain precipitation of the desired crystalline phase.

Optical properties of the $\mathrm{Eu}^{3+}$ ions were used to investigate local structure and xerogel to glass ceramic transformations in $\mathrm{SiO}_{2}-\mathrm{NaYF}_{4}$ [67] and $\mathrm{SiO}_{2}-\mathrm{LiYF}_{4}$ [30] glass ceramics. For $\mathrm{Eu}^{3+}$-doped $\mathrm{SiO}_{2}-\mathrm{NaYF}_{4}$ glass ceramics, cubic-NaYF 4 nanocrystals of about 4-10 $\mathrm{nm}$ size precipitated during the thermal processing [67]. Site selective spectroscopy measurements allowed discerning ions in the amorphous silica glassy phase from those preferentially partitioned into a like-crystalline environment. Hence, a noticeable enhancement of the $613 \mathrm{~nm}$ luminescence from 3.1 to $5.7 \mathrm{~ms}$ by changing from amorphous surroundings (exciting at $464 \mathrm{~nm}$ ) to those ions partitioned into nanocrystals (exciting at $392 \mathrm{~nm}$ ) was observed. Moreover, the red to green emissions ratio $\left({ }^{5} \mathrm{D}_{0}-{ }^{7} \mathrm{~F}_{2} /{ }^{5} \mathrm{D}_{0}-{ }^{7} \mathrm{~F}_{1}\right)$ diminishes with the heat treatment indicating the partition of $\mathrm{Eu}^{3+}$ ions in the nanocrystals. In the $\mathrm{SiO}_{2}-\mathrm{LiYF}_{4}[72,73]$ glass ceramic, the precipitation of the $\mathrm{LiYF}_{4}$ nanocrystals was observed only for high $\mathrm{Li}$ excess (up to four molar Li/Y ratio). For a lower molar ratio, a glass-ceramic containing a mixture of $\mathrm{YF}_{3}$ and $\mathrm{LiYF}_{4}$ crystals or only $\mathrm{YF}_{3}$ phase (i.e., for stoichiometric ratio) was obtained [73]. The enhancement of $\mathrm{Eu}^{3+}$-lifetime values from $0.22 \mathrm{~ms}$ in the xerogel to $8.68 \mathrm{~ms}$ and the diminishing of the red to green emissions ratio were associated to the xerogel to glass ceramic transformation and $\mathrm{Eu}^{3+}$ ions partition in the nanocrystals [30]. Moreover, the group-theoretical analysis of the photoluminescence spectra has indicated that the $\mathrm{Eu}^{3+}$ ions incorporation occurs dominantly inside the $\mathrm{LiYF}_{4}$ nanocrystals with lower symmetry $\left(\mathrm{C}_{2 \mathrm{v}}\right)$ sites than in polycrystalline pellet $\left(\mathrm{D}_{2 \mathrm{~d}}\right)$.

Transparent oxyfluoride glass-ceramics comprising $\mathrm{Yb}^{3+} / \mathrm{Er}^{3+}$ co-doped $\mathrm{LiYF}_{4}$ and $\mathrm{NaYF}_{4}$ nanocrystals showed green $\left(\left({ }^{2} H_{11 / 2},{ }^{4} S_{3 / 2}\right) \rightarrow{ }^{4} I_{15 / 2}\right)$ and red $\left({ }^{4} F_{9 / 2} \rightarrow{ }^{4} I_{15 / 2}\right)$ visible up-conversion luminescence due to the $\mathrm{Er}^{3+}$ ions incorporated in precipitated nanocrystals [73,74]. For Er/Yb co-doped $\mathrm{SiO}_{2}-\mathrm{LiYF}_{4}$ glass ceramic, the values of the quantum efficiencies for the red and green UC luminescences are much lower in the glass ceramic ( $\eta=2 \%$ and $\eta=3.5 \%)$ compared to the pellet $(\eta=46 \%$ and $\eta=21 \%$ ) [73], but similar to the $\mathrm{Er} / \mathrm{Yb}$ co-doped glass ceramic containing $\mathrm{CaF}_{2}$ nanocrystals [40]. Moreover, the ratio between red and green up-conversion emission bands can be varied as 
a function of processing temperature and pump power resulting in color tunable upconversion phosphors [74].

The investigations of the $\mathrm{Nd}^{3+}$-doped $\mathrm{SiO}_{2}-\mathrm{NaLaF}_{4}$ glass ceramic showed both $\mathrm{LaF}_{3} / \mathrm{NaLaF}_{4}$ crystalline phases for different initial compositions and annealing temperatures; the crystallization of $\mathrm{NaLaF}_{4}$ was only promoted for Na deficiency in the precursors and higher temperatures calcination, above $650{ }^{\circ} \mathrm{C}$ [68]. The incorporation of $\mathrm{Nd}^{3+}$ ion into $\mathrm{NaLaF}_{4}$ and $\mathrm{LaF}_{3}$ nanocrystals was confirmed by site-selective emission and excitation spectra (Figure 16).

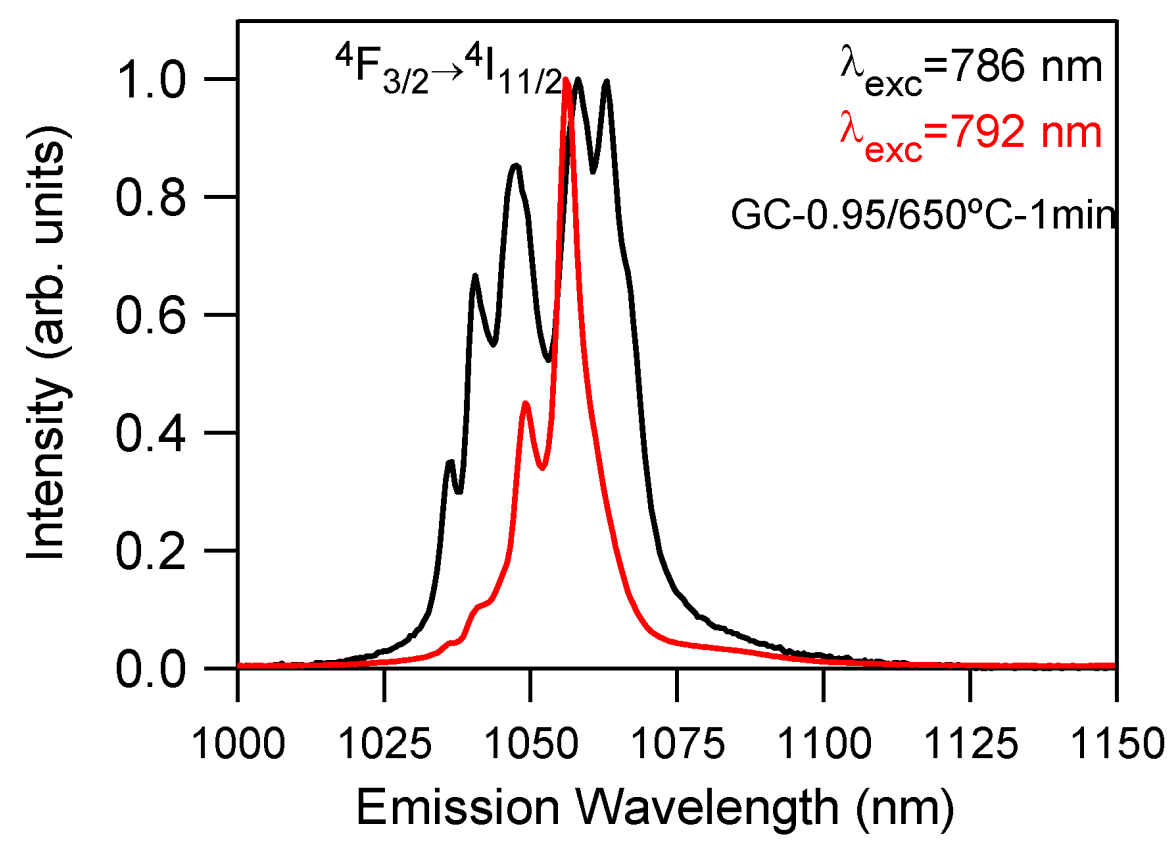

Figure 16. Normalized emission spectra of the ${ }^{4} \mathrm{~F}_{3 / 2} \rightarrow{ }^{4} \mathrm{I}_{11 / 2}$ transition obtained under excitation at 786 (black) and $792 \mathrm{~nm}$ (red) of the GC-0.95 sample doped with $0.1 \mathrm{~mol} \%$ of $\mathrm{Nd}^{3+}$ corresponding to $\mathrm{Nd}^{3+}$ ions in $\mathrm{LaF}_{3}$ and $\mathrm{NaLaF}_{4}$ crystalline phases, respectively [68].

For the $\mathrm{SiO}_{2}-\mathrm{NaGdF}_{4}$ glass ceramic, the precipitation of cubic and/or hexagonal $\mathrm{NaGdF}_{4}$ nanocrystals with a size ranging between 4 and $24 \mathrm{~nm}$ was observed, depending on the Na:Gd ratio and processing conditions (temperature and time) [69]. The Na:Gd ratio was optimized to obtain the crystallization of $\beta-\mathrm{NaGdF}_{4}$ phase, more adequate for luminescent applications and for a molar ratio $0.95: 1$, the precipitation of $\beta-\mathrm{NaGdF}_{4}$ (JCPDS 027-0699) phase was observed after treatment at $550{ }^{\circ} \mathrm{C}$. Luminescence results showed $\mathrm{Eu}^{3+}$ ions' incorporation mainly in $\mathrm{NaGdF}_{4} \mathrm{NCs}$, and an efficient energy transfer $\mathrm{Gd}^{3+}$ to $\mathrm{Eu}^{3+}$ was observed. Electron microscopy investigations of $\mathrm{SiO}_{2}-\mathrm{KLaF}_{4}$ glass ceramics confirmed the coexistence of cubic ( $\alpha$-phase) and hexagonal ( $\beta$-phase) $\mathrm{KLaF}_{4}$ phases, the last one being favored for high temperature calcination [70]. The spectral features of the $\mathrm{Nd}^{3+}$ ions dopants confirmed the incorporation of $\mathrm{Nd}^{3+}$ ions in both crystalline phases, with emission of $\mathrm{Nd}^{3+}$ predominantly in the $\beta-\mathrm{KLaF}_{4}$ hexagonal phase.

The UV light excitation of $\mathrm{Ce}^{3+} / \mathrm{Tb}^{3+} / \mathrm{Eu}^{3+}$ triply-doped $\mathrm{SiO}_{2}-\mathrm{KYF}_{4}$ glass ceramics is accompanied by an efficient ET processes between $\mathrm{Ce}^{3+}$ and $\mathrm{Tb}^{3+} / \mathrm{Eu}^{3+}$ ions, followed by their characteristic green and reddish-orange emission, respectively [71]. The emitted color can be tuned by varying the content of $\mathrm{Eu}^{3+}$ ions and/or the excitation wavelength, and white light generation was reached (Figure 17). In $\mathrm{SiO}_{2}-\mathrm{KYF}_{4}$ transparent glassceramics comprising $\mathrm{Yb}^{3+}, \mathrm{Er}^{3+}, \mathrm{Tm}^{3+}$ co-doped $\mathrm{KYF}_{4}$ nanocrystals, white light generation was obtained by simultaneous red, green, and blue additive up-conversion emissions of the $\mathrm{RE}^{3+}$-ions dopants [75]. 


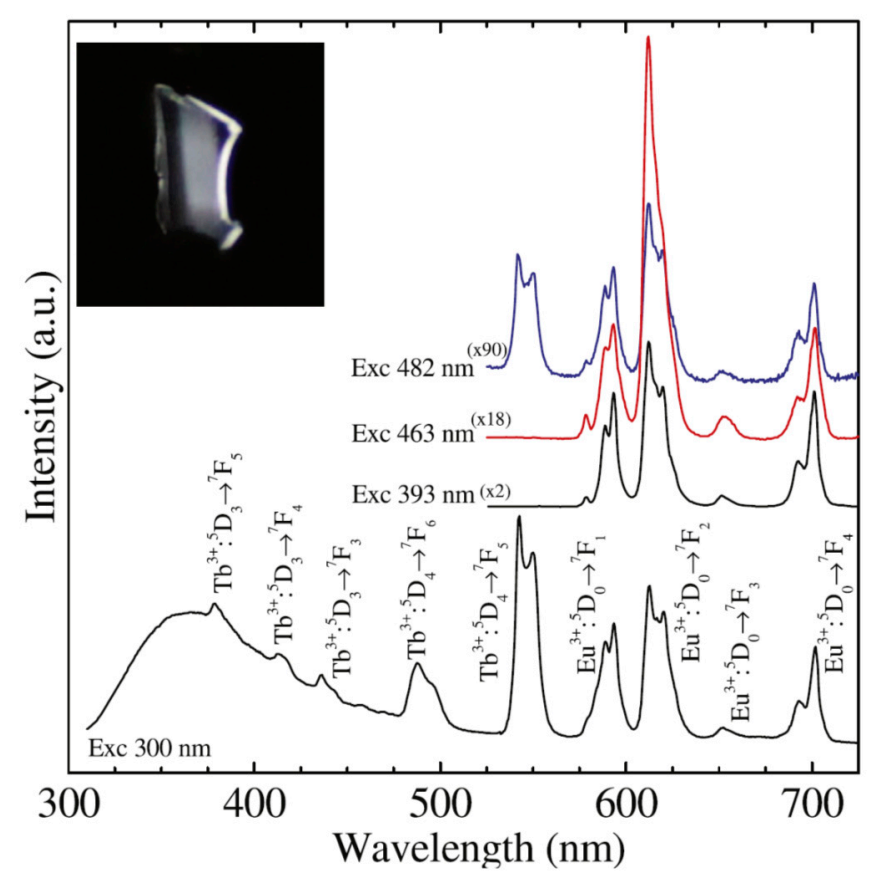

Figure 17. Emission spectra of $0.3 \mathrm{Ce}^{3+} / 0.3 \mathrm{~Tb}^{3+} / 0.6 \mathrm{Eu}^{3+}(\mathrm{mol} \%)$ triply-doped $\mathrm{SiO}_{2}-\mathrm{KYF}_{4}$ glass ceramics under UV excitation of $\mathrm{Ce}^{3+}$ by comparison to the direct excitation of $\mathrm{Eu}^{3+}$ and $\mathrm{Tb}^{3+}$ ions, showing the $\mathrm{Eu}^{3+}$ and $\mathrm{Tb}^{3+}$ luminescence peaks (reproduced from reference [71]).

More complex sol-gel glass ceramics, containing $\mathrm{RE}^{3+}$-doped $\mathrm{BaYF}_{5}$ and $\mathrm{BaGdF}_{5}$ nanocrystals embedded in silica matrix, have been produced by appropriate annealing of the corresponding precursor xerogel [76,77]. Optical measurements confirmed the distribution of a significant fraction of $\mathrm{RE}^{3+}$ ions into the precipitated $\mathrm{BaYF}_{5}$ fluoride nanocrystals environment [76]. For $\mathrm{RE}^{3+}$-doped $\left(\mathrm{Eu}^{3+}, \mathrm{Sm}^{3+}, \mathrm{Dy}^{3+}\right.$ or $\left.\mathrm{Tb}^{3+}\right)$ glass ceramics containing $\mathrm{BaGdF}_{5}$ nanocrystals, intense visible emissions through efficient energy transfer from $\mathrm{Gd}^{3+}$ to $\mathrm{RE}^{3+}$ ions were observed, which leads to consider these materials as potential emitting phosphors for color converted UV LED [77]. Sol-gel glass ceramics comprising $\mathrm{Tm}^{3+}$ co-doped $\mathrm{SiO}_{2}-\mathrm{BaY}_{0.78-\mathrm{x}} \mathrm{Gd}_{\mathrm{x}} \mathrm{Yb}_{0.2} \mathrm{Tm}_{0.02} \mathrm{~F}_{5}$ ( $\mathrm{x}=0-0.78$ ) nanocrystals showed UC luminescence in the NIR, visible, and UV range assigned to the $\mathrm{Tm}^{3+}$-dopant ions distributed into nanocrystalline environments [78]. The substitution of $\mathrm{Y}^{3+}$ by $\mathrm{Gd}^{3+}$ leads to a continuous decrease of the UV emission intensities due to an effective energy transfer between $\mathrm{Tm}^{3+}$ and $\mathrm{Gd}^{3+}$ ions.

As $\mathrm{RE}^{3+}$-doped Lu-based fluorides are investigated for their applications as scintillators due to high absorption cross-section for any kind of radiation, the sol-gel route has been used to prepare RE-doped $\mathrm{SiO}_{2}-\mathrm{Sr}_{2} \mathrm{LuF}_{7}$ glass ceramics and their structural and optical properties investigated [79]. The luminescent features of $\mathrm{Eu}^{3+}$ ions, used as structural probes, revealed the distribution of $\mathrm{RE}^{3+}$ ions in both glass matrix and fluoride nanocrystals. Under $980 \mathrm{~nm}$ laser excitation of $\mathrm{Yb}^{3+}-\mathrm{Tm}^{3+}, \mathrm{Yb}^{3+}-\mathrm{Er}^{3+}$ and $\mathrm{Yb}^{3+}-\mathrm{Ho}^{3+}$ co-doped glass ceramics, intense UV, vis and NIR up-conversion emissions were observed.

\section{Oxychloride Glass Ceramic}

Sol-gel glass ceramics containing $\mathrm{Er}^{3+}$-doped $\mathrm{BaCl}_{2}$ nanocrystals of about tens of $\mathrm{nm}$ size embedded in a silica matrix were prepared but by replacing TFA with trichloroacetic acid $\left(\mathrm{CCl}_{3} \mathrm{COOH}\right)$ [80]. The crystallization process relies on thermal decomposition of Ba-trichloroacetate at about $300{ }^{\circ} \mathrm{C}$ followed by subsequent growth into $\mathrm{BaCl}_{2}$-nanocrystals at $745^{\circ} \mathrm{C} ; \mathrm{Er}^{3+}$-ions are incorporated during the nanocrystals' growth. Under $810 \mathrm{~nm}$ laser light pumping, it shows green $\left(\left({ }^{2} H_{11 / 2},{ }^{4} S_{3 / 2}\right) \rightarrow{ }^{4} I_{15 / 2}\right)$ and red $\left({ }^{4} F_{9 / 2} \rightarrow{ }^{4} I_{15 / 2}\right) \mathrm{Er}^{3+}$ upconversion luminescences, much weaker (only about $10 \%)$ compared to $\mathrm{NaYF}_{4}: \mathrm{Er}^{3+}(18 \%)$. Glassy nanocomposites containing $\mathrm{Eu}^{3+}$-doped $\mathrm{LaOCl}$ nanocrystals of about tens of $\mathrm{nm}$ 
size embedded in a silica matrix were prepared with the sol-gel route using trichloroacetic acid $\left(\mathrm{CCl}_{3} \mathrm{COOH}\right)$ as a chlorination agent [81]. It was shown that the $\mathrm{LaOCl}$ nanocrystalline phase precipitation is the result of the lanthanum chloride hydrolytic and oxidative reactions. As the annealing temperature increases, nanocrystals grow up to tens of $\mathrm{nm}$ size and $\mathrm{Eu}^{3+}$-ions are gradually incorporated inside the $\mathrm{LaOCl}$ nanocrystals, with a $\left(C_{4 \mathrm{v}}\right)$ local coordination symmetry.

\section{Perspectives and Applications}

In summary, the synthesis and investigations of sol-gel derived oxyfluoride glass ceramics are based and limited to the synthesis initially developed by Fujihara et al. [5-7], using TMOS and/or TEOS as the $\mathrm{SiO}_{2}$ precursor and TFA as the fluorine source and active fluoride crystalline phase fraction of about $5 \%$, much lower than in melt-quenched glass ceramics. Most of the research efforts were dedicated to oxyfluoride glass ceramics, being focused primarily on optical (luminescence) properties of the RE-doped nanocrystals. Therefore, future research efforts are expected to be dedicated to the discovery of new glass ceramic materials with multifunctional properties (optical, electric, and magnetic) for new and improved applications.

Transparent glass ceramic waveguides offer specific characteristics of capital importance in photonics and the sol-gel approach has proved to be a very convenient and flexible way to deposit glass ceramic thin films on a variety of substrates for different applications, such as planar waveguides or integrated optics. New glass ceramic thin films comprising RE-doped oxide semiconducting nanocrystals such as $\mathrm{SnO}_{2}, \mathrm{ZrO}_{2}, \mathrm{CeO}_{2}, \mathrm{HfO}_{2}$ have been already obtained and optical properties studied [82-86]. The investigations of both optical and electric properties would be interesting for both basic and applied research.

New developments of the glass ceramic films can include patterned glass ceramic thin films that can be produced by using laser-induced crystallization [87] allowing the development of active integrated optical circuits. Moreover, a higher crystallized fraction of the nominal active fluoride crystalline phase is expected to improve the optical properties. Recent studies have shown that crack-free $\mathrm{SiO}_{2}-\mathrm{LaF}_{3}$ glass ceramic films with a crystalline $\mathrm{LaF}_{3}$ crystalline fraction of $18 \mathrm{wt} \%$ can be obtained [18].

The investigations of glass ceramics with $\mathrm{Gd}^{3+}$-based fluorides nanocrystals embedded in the glass matrix were limited to the analysis of luminescence properties of the co-dopant RE-ions [61-63]. The magnetic properties related to $\mathrm{Gd}^{3+}$ ions and the influence of the magnetic field on optical properties, in particular on the energy transfer processes, have been overlooked/missed. Such novel, multifunctional magneto-optical materials allow the intertwining between the magnetism and photonics and might offer new opportunities for magneto-optical devices.

Sol-gel synthesis has been used to obtain not only thin films but also monolithic silica and glass ceramics $[88,89]$ opening the opportunity to produce monolithic scintillating glass ceramics based on $\mathrm{BaF}_{2}, \mathrm{CaF}_{2}, \mathrm{CeF}_{3}$ and $\mathrm{BaCl}_{2}$. Proper co-doping with broad blue absorbing sensitizer ions $\left(\mathrm{Bi}^{3+}, \mathrm{Sn}^{3+}\right.$, etc.) capable to transfer their excitation energy to neighboring activator ions might develop potential spectral down-conversion applications.

The optical properties investigations of glass ceramics were focused only on trivalent ions related ones and divalent $\mathrm{Eu}^{2+}$ and $\mathrm{Sm}^{2+}$ ions were omitted. Previous investigations $[90,91]$ have shown the incorporation of the reduced $\mathrm{Eu}^{2+}$ and $\mathrm{Sm}^{2+}$ ions in sol-gel glasses (not ceramic ones) under moderate conditions of temperature and atmosphere in two steps, glass-formation, and their reduction to the bivalent state by calcination in reducing atmosphere. $\mathrm{Eu}^{2+}$ and $\mathrm{Sm}^{2+}$ ions have attracted significant attention because they have a great potential for various photonics-related applications or radiation detection. The $\mathrm{Sm}^{2+}$ ion shows persistent spectral hole burning (PSHB) and potential application for high density optical memories. On the other hand, $\mathrm{Eu}^{2+}$ doping is crucial for scintillators detectors or X-ray storage phosphor for digital imaging applications. However, the incorporation of such bivalent ions into the precipitated nanocrystals from the glass ceramics still remain an open problem. 
A new approach for sol-gel glass ceramics was recently proposed by Cruz M.E. et al. (2020) [92], where dispersed nanocrystals were incorporated in the silica glass matrix. This approach allows the incorporation in the silica glass matrix of a much broader range of nanocrystalline phosphors such as $\mathrm{Eu}^{2+}$-doped persistent phosphors [93] or $\mathrm{Sm}^{3+}$-doped $\mathrm{BaFCl}$ for multilevel optical data storage applications [94].

As the optical properties are strongly influenced by the hydroxyl ions (present even after high temperatures calcination), new non-aqueous sol-gel approaches are highly desirable $[95,96]$. A first step was made by using hydrofluoric acid catalyzed sol-gel process [95] and the non-aqueous fluorolytic sol-gel synthesis of metal nano-fluorides [96].

\section{Conclusions}

In conclusion, sol-gel derived glass ceramic materials based on stabilized rare-earth doped nanoparticles embedded in a glass matrix were demonstrated as novel, attractive materials for photonics applications. However, the advantages of sol-gel chemistry and thin films' deposition ability have not been fully exploited for advances in both basic and applied research. Therefore, the development of new glass ceramic materials with multifunctional properties for new and improved applications is highly desirable.

Author Contributions: The manuscript was written by M.S. in collaboration with C.S. and C.B. All the authors contributed to discussions and reviewed the manuscript. All authors have read and agreed to the published version of the manuscript.

Funding: This research was funded by the Romanian Ministry of Research and Innovation (MCI) through the PN19-03 Core Program of NIMP (2020).

Conflicts of Interest: The authors declare no conflict of interest.

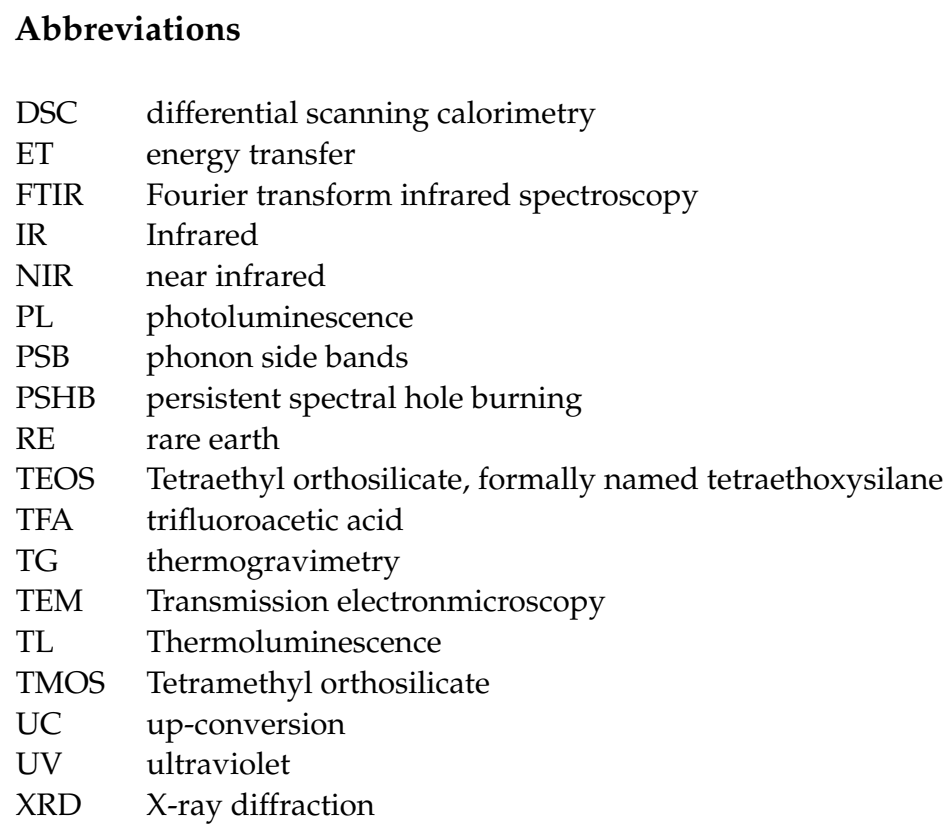

\section{References}

1. Deubener, J.; Allix, M.; Davis, M.J.; Duran, A.; Höche, T.; Honma, T.; Komatsu, T.; Krüger, S.; Mitra, I.; Müller, R.; et al. Updated definition of glass-ceramics. J. Non-Cryst. Solids 2018, 501, 3-10. [CrossRef]

2. Pablos-Martin, A.; Duran, A.; Pascual, M.J. Nanocrystallisation in oxyfluoride systems: Mechanisms of crystallization and photonic properties. Int. Mater. Rev. 2012, 57, 165-186. [CrossRef]

3. Brinker, C.J.; Scherer, G. Sol-Gel Science: The Physics and Chemistry of Sol-Gel Processing, 1st ed.; Academic Press Inc.: New York, NY, USA, 1990; Levy, D.; Zayat, M. The Sol-Gel Handbook: Synthesis, Characterization and Applications; Wiley-VCH: Weinheim, Germany, 2015.

4. Gorni, G.; Velázquez, J.J.; Mosa, J.; Balda, R.; Fernández, J.; Durán, A.; Castro, Y. Transparent Glass-Ceramics Produced by Sol-Gel: A Suitable Alternative for Photonic Materials. Materials 2018, 11, 212. [CrossRef] 
5. Fujihara, S.; Mochizuki, C.; Kimura, T. Formation of LaF3 microcrystals in sol-gel silica. J. Non-Cryst. Solids 1999, 244, 267-274. [CrossRef]

6. Fujihara, S.; Kato, T.; Kimura, T. Influence of solution composition on the formation of $\mathrm{SiO}_{2} / \mathrm{LaF}_{3}$ composites in the sol-gel process. J. Mater. Sci. 2000, 35, 2763-2767. [CrossRef]

7. Fujihara, S.; Tada, M.; Kimura, T. Preparation and characterization of $\mathrm{MgF}_{2}$ thin film by a trifluoroacetic acid method. Thin Solid Films 1997, 304, 252-255. [CrossRef]

8. Secu, C.E.; Bartha, C.; Polosan, S.; Secu, M. Thermally activated conversion of a silicate gel to an oxyfluoride glass ceramic: Optical study using $\mathrm{Eu}^{3+}$ probe ion. J. Lumin. 2014, 146, 539-543. [CrossRef]

9. Almeida, R.M.; Goncalves, M.C. Crystallization of Sol-gel Derived Glasses. Int. J. Appl. Glass Sci. 2014, 5, 114-125. [CrossRef]

10. Gorni, G.; Pascual, M.J.; Caballero, A.; Velázquez, J.J.; Mosa, J.; Castro, Y.; Durán, A. Crystallization mechanism in sol-gel oxyfluoride glass-ceramics. J. Non-Cryst. Solids 2018, 501, 145-152. [CrossRef]

11. Yu, Y.; Chen, D.; Wang, Y.; Luo, W.; Zheng, Y.; Cheng, Y.; Zhou, L. Structural evolution and its influence on luminescence of $\mathrm{SiO}_{2}-\mathrm{SrF}_{2}-\mathrm{ErF}_{3}$ glass ceramics prepared by sol-gel method. Mater. Chem. Phys. 2006, 100, 241-245. [CrossRef]

12. Szpikowska-Sroka, B.; Zur, L.; Czoik, R.; Goryczka, T.; Swinarew, A.S.; Zadło, M.; Pisarski, W.A. Long-lived emission from $\mathrm{Eu}^{3+}$-doped $\mathrm{PbF}_{2}$ nanocrystals distributed into sol-gel silica glass. J. Sol-Gel Sci. Technol. 2013, 68, 278-283. [CrossRef]

13. Luo, W.; Wang, Y.; Cheng, Y.; Bao, F.; Zhou, L. Crystallization and structural evolution of $\mathrm{SiO}_{2}-\mathrm{YF}_{3}$ xerogel. Mater. Sci. Eng. B 2006, 127, 218-223. [CrossRef]

14. Farjasa, J.; Campsa, J.; Rouraa, P.; Ricartb, S.; Puigb, T.; Obradors, X. The thermal decomposition of barium trifluoroacetate. Thermochim. Acta 2012, 544, 77-83. [CrossRef]

15. Secu, M.; Secu, C.E.; Ghica, C. Eu ${ }^{3+}$-doped $\mathrm{CaF}_{2}$ nanocrystals in sol-gel derived glass-ceramics. Opt. Mater. 2011, 33, 613-617. [CrossRef]

16. Rüssel, C. Thermal decomposition of metal trifluoracetates. J. Non-Cryst. Solids 1993, 152, 161-166. [CrossRef]

17. Nogami, M.; Abe, Y. Properties of sol-gel-derived $\mathrm{Al}_{2} \mathrm{O}_{3}-\mathrm{SiO}_{2}$ glasses using $\mathrm{Eu}^{3+}$ ion fluorescence spectra. J. Non-Cryst. Solids 1996, 197, 73-78. [CrossRef]

18. Gorni, G.; Velázquez, J.J.; Mosa, J.; Mather, G.C.; Serrano, A.; Vila, M.; Castro, G.R.; Bravo, D.; Balda, R.; Fernández, J.; et al. Transparent Sol-Gel Oxyfluoride Glass-Ceramics with High Crystalline Fraction and Study of RE Incorporation. Nanomaterials 2019, 9, 530. [CrossRef] [PubMed]

19. Secu, C.E.; Secu, M.; Ghica, C.; Mihut, L. Rare-earth doped sol-gel derived oxyfluoride glass-ceramics: Structural and optical characterization. Opt. Mater. 2011, 33, 1770-1774. [CrossRef]

20. Pawlik, N.; Szpikowska-Sroka, B.; Pietrasik, E.; Goryczka, T.; Pisarski, W.A. Structural and luminescence properties of silica powders and transparent glass-ceramics containing $\mathrm{LaF}_{3}: \mathrm{Eu}^{3+}$ nanocrystals. J. Am. Ceram. Soc. 2018, 101, 4654-4668. [CrossRef]

21. Bartha, C.; Secu, C.E.; Matei, E.; Negrila, C.; Leca, A.; Secu, M. Towards a Correlation between Structural, Magnetic, and Luminescence Properties of $\mathrm{CeF}_{3}: \mathrm{Tb}^{3+}$ Nanocrystals. Materials 2020, 13, 2980. [CrossRef]

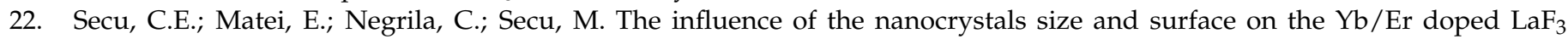
luminescence properties. J. Alloys Compd. 2019, 791, 1098-1104. [CrossRef]

23. Yanes, A.C.; Santana-Alonso, A.; Méndez-Ramos, J.; del Castillo, J.; Rodriguez, V.D. Novel Sol-Gel Nano-Glass-Ceramics Comprising $\mathrm{Ln}^{3+}$-Doped $\mathrm{YF}_{3}$ Nanocrystals: Structure and High Efficient UV Up-Conversion. Adv. Funct. Mater. 2011, 21, 3136-3142. [CrossRef]

24. Binnemans, K.; Gorller-Walrand, C. Application of the $\mathrm{Eu}^{3+}$ ion for site symmetry determination. J. Rare Earths 1996, 14, 173-180.

25. Driesen, K.; Tikhomirov, V.K.; Gorller-Walrand, C. Eu ${ }^{3+}$ as a probe for rare-earth dopant site structure in nano-glass-ceramics. J. Appl. Phys. 2007, 102, 024312. [CrossRef]

26. Lochhead, M.J.; Bray, K.L. Spectroscopic characterization of doped sol-gel silica gels and glasses: Evidence of inner-sphere complexation of europium(III). J. Non-Cryst. Solids 1994, 170, 143-154. [CrossRef]

27. Devlin, K.; O’ Kelly, B.; Tang, Z.R.; McDonagh, C.; McGilp, J.F. A structural study of the sol-gel process by optical fluorescence and decay time spectroscopy. J. Non-Cryst. Solids 1991, 135, 8-14. [CrossRef]

28. Secu, C.E.; Polosan, S.; Secu, M. Magneto-optical investigations of rare earth doped sol-gel derived silicate xerogel. J. Lumin. 2011, 131, 1747-1752. [CrossRef]

29. Reisfeld, R.; Zigansky, E.; Gaft, M. Europium probe for estimation of site symmetry in glass films, glasses and crystals. Mol. Phys. 2004, 102, 1319-1330. [CrossRef]

30. Secu, C.E.; Negrea, R.F.; Secu, M. Eu ${ }^{3+}$ probe ion for rare-earth dopant site structure in sol-gel derived LiYF 4 oxyfluoride glass-ceramic. Opt. Mater. 2013, 35, 2456-2460. [CrossRef]

31. Auzel, F. Upconversion and Anti-Stokes Processes with f and d Ions in Solids. Chem. Rev. 2004, 104, 139-174. [CrossRef]

32. Secu, M. Up-conversion properties of sol-gel derived $\mathrm{Yb}^{3+} / \mathrm{Er}^{3+}$-doped oxyfluoride glass-ceramics. unpublished work.

33. McKeever, S.W.S. Thermoluminescence of Solids; Cambridge University Press: New York, NY, USA, 1985.

34. Bos, A.J.J. Thermoluminescence as a Research Tool to Investigate Luminescence Mechanisms. Materials 2017, 10, 1357. [CrossRef] [PubMed]

35. Bos, A.J.J.; Dorenbos, P.; Bessière, A.; Viana, B. Lanthanide energy levels in $\mathrm{YPO}_{4}$. Radiat. Meas. 2008, 43, 222-226. [CrossRef]

36. Krumpel, A.H.; van der Kolk, E.; Zeelenberg, D.; Bos, A.J.J.; Krämer, K.W.; Dorenbos, P. Lanthanide 4f-level location in lanthanide doped and cerium-lanthanide codoped $\mathrm{NaLaF}_{4}$ by photo- and thermoluminescence. J. Appl. Phys. 2008, 104, 073505. [CrossRef] 
37. Rodnyi, P.A.; Khodyuk, I.V.; Stryganyuk, G.B. Location of the Energy Levels of the Rare-Earth Ion in $\mathrm{BaF}_{2}$ and $\mathrm{CdF}_{2}$. Phys. Solid State 2008, 50, 1639-1643. [CrossRef]

38. Secu, M.; Secu, C.; Sima, M. Sol-gel template synthesis of luminescent glass-ceramic rods. J. Nanopart. Res. $2012,14,772$. [CrossRef]

39. Zhou, L.; Chen, D.; Luo, W.; Wang, Y.; Yu, Y.; Liu, F. Transparent glass ceramic containing $\mathrm{Er}^{3+}: \mathrm{CaF}_{2}$ nano-crystals prepared by sol-gel method. Mater. Lett. 2007, 61, 3988-3990. [CrossRef]

40. Georgescu, S.; Voiculescu, A.M.; Matei, C.; Secu, C.E.; Negrea, R.F.; Secu, M. Ultraviolet and visible up-conversion luminescence of $\mathrm{Er}^{3+} / \mathrm{Yb}^{3+}$ co-doped $\mathrm{CaF}_{2}$ nanocrystals in sol-gel derived glass-ceramics Journal ofLuminescence. J. Lumin. 2013, 143, 150-156. [CrossRef]

41. Kłonkowski, A.M.; Wiczk, W.; Ryl, J.; Szczodrowski, K.; Wileńska, D. A white phosphor based on oxyfluoride nano-glass-ceramics codoped with $\mathrm{Eu}^{3+}$ and $\mathrm{Tb}^{3+}$ : Energy transfer study $\left(\mathrm{SrF}_{2}\right)$. J. Alloys Compd. 2017, 724, 649-658. [CrossRef]

42. Yu, Y.; Wang, Y.; Chen, D.; Liu, F. Efficient upconversion luminescence of $\mathrm{Er}^{3+}: \mathrm{SrF}_{2}-\mathrm{SiO}_{2}-\mathrm{Al}_{2} \mathrm{O}_{3}$ sol-gel glass ceramics. Ceram. Int. 2008, 34, 2143-2146. [CrossRef]

43. Chen, D.; Wang, Y.; Yu, Y.; Ma, E.; Zhou, L. Microstructure and luminescence of transparent glass ceramic containing $\mathrm{Er}^{3+}: \mathrm{BaF}_{2}$ nano-crystals. J. Solid State Chem. 2006, 179, 532-537. [CrossRef]

44. Luo, W.; Wang, Y.; Bao, F.; Zhou, L.; Wang, X. Crystallization behavior of PbF2-SiO2 based bulk xerogels. J. Non-Cryst. Solids 2004, 347, 31-38. [CrossRef]

45. Szpikowska-Sroka, B.; Pawlik, N.; Goryczka, T.; Pietrasik, E.; Bańczyk, M.; Pisarski, W.A. Lead fluoride $\beta-$ PbF $_{2}$ nanocrystals containing $\mathrm{Eu}^{3+}$ and $\mathrm{Tb}^{3+}$ ions embedded in sol-gel materials: Thermal, structural and optical investigations. Ceram. Int. 2017, 43, 8424-8432. [CrossRef]

46. Szpikowska-Sroka, B.; Pawlik, N.; Goryczka, T.; Pisarski, W.A. Eu ${ }^{3+/} \mathrm{Tb}^{3+}$ codoped $\mathrm{PbF}_{2}$ nanocrystals in sol-gel glass-ceramic materials: Fabrication, structure and properties. Mater. Sci. Eng. B 2021, 263, 114884. [CrossRef]

47. Del-Castillo, J.; Yanes, A.C.; Méndez-Ramos, J.; Tikhomirov, V.K.; Rodríguez, V.D. Structure and up-conversion luminescence in sol-gel derived $\mathrm{Er}^{3+}-\mathrm{Yb}^{3+}$ co-doped $\mathrm{SiO}_{2}: \mathrm{PbF}_{2}$ nano-glass-ceramics. Opt. Mater. 2009, 32, 104-107. [CrossRef]

48. Del-Castillo, J.; Yanes, A.C.; Mendez-Ramos, J.; Tikhomirov, V.K.; Moshchalkov, V.V.; Rodriguez, V.D. Sol-gel preparation and white up-conversion luminescence in rare-earth doped $\mathrm{PbF}_{2}$ nanocrystals dissolved in silica glass. J. Sol-Gel. Sci. Technol. 2010, 53, 509-514. [CrossRef]

49. Yanes, A.C.; del-Castillo, J.; Mendez-Ramos, J.; Rodriguez, V.D.; Torres, M.E.; Arbiol, J. Luminescence and structural characterization of transparent nanostructured $\mathrm{Eu}^{3+}$-doped $\mathrm{LaF}_{3}-\mathrm{SiO}_{2}$ glass-ceramics prepared by sol-gel method. Opt. Mater. 2007, 29, 999-1003. [CrossRef]

50. Pawlik, N.; Szpikowska-Sroka, B.; Goryczka, T.; Pisarski, W.A. Studies of Sol-Gel Evolution and Distribution of Eu ${ }^{3+}$ Ions in Glass-Ceramics Containing $\mathrm{LaF}_{3}$ Nanocrystals Depending on Initial Sols Composition. Int. J. Mol. Sci. 2021, 22, 996. [CrossRef] [PubMed]

51. Pawlik, N.; Szpikowska-Sroka, B.; Pitrasik, E.; Goryczka, T.; Dulski, M.; Swinarew, A.S.; Zubko, M.; Lelątko, J.; Pisarski, W.A. Reddish-orange $\mathrm{Eu}^{3+}$-doped sol-gel emitters based on $\mathrm{LaF}_{3}$ nanocrystals-Synthesis, structural and photoluminescence investigations. Opt. Mater. 2019, 89, 276-282. [CrossRef]

52. Rodriguez, V.D.; del Castillo, J.; Yanes, A.C.; Mendez-Ramos, J.; Torres, M.; Peraza, J. Luminescence of Er ${ }^{3+}$-doped nanostructured $\mathrm{SiO}_{2}-\mathrm{LaF}_{3}$ glass-ceramics prepared by the sol-gel method. Opt. Mater. 2007, 29, 1557-1561. [CrossRef]

53. Biswas, A.; Maciel, G.S.; Friend, C.S.; Prasad, P.N. Upconversion properties of a transparent $\mathrm{Er}^{3+}-\mathrm{Yb}^{3+} \mathrm{Co}_{-} \mathrm{doped} \mathrm{LaF}_{3}-\mathrm{SiO}_{2}$ glass-ceramics prepared by sol-gel method. J. Non-Cryst. Solids 2003, 16, 393-397. [CrossRef]

54. Méndez-Ramos, J.; Velázquez, J.J.; Yanes, A.C.; del-Castillo, J.; Rodríguez, V.D. Up-conversion in nanostructured $\mathrm{Yb}^{3+}-\mathrm{Tm}^{3+}$ co-doped sol-gel derived $\mathrm{SiO}_{2}-\mathrm{LaF}_{3}$ transparent glass-ceramics. Phys. Status Solidi A 2008, 205, 330-334. [CrossRef]

55. Velázquez, J.J.; Yanes, A.C.; del Castillo, J.; Méndez-Ramos, J.; Rodríguez, V.D. Optical properties of $\mathrm{Ho}^{3+}-\mathrm{Yb}^{3+} \mathrm{co}^{3} \mathrm{doped}$ nanostructured $\mathrm{SiO}_{2}-\mathrm{LaF}_{3}$ glass-ceramics prepared by sol-gel method. Phys. Status Solidi A 2007, 204, 1762-1768. [CrossRef]

56. Yanes, A.C.; Velaszquez, J.J.; del-Castillo, J.; Mendez-Ramos, J.; Rodrıguez, V.D. Colour tuneability and white light generation in $\mathrm{Yb}^{3+}-\mathrm{Ho}^{3+}-\mathrm{Tm}^{3+}$ co-doped $\mathrm{SiO}_{2}-\mathrm{LaF}_{3}$ nano-glass-ceramics prepared by sol-gel method. J. Sol-Gel Sci. Technol. 2009, 51, 4-9. [CrossRef]

57. Pawlik, N.; Szpikowska-Sroka, B.; Goryczka, T.; Zubko, M.; Lelatko, J.; Pisarski, W.A. Structure and luminescent properties of oxyfluoride glass-ceramics with $\mathrm{YF}_{3}: \mathrm{Eu}^{3+}$ nanocrystals derived by sol-gel method. J. Eur. Ceram. Soc. 2019, 39, $5010-5017$. [CrossRef]

58. Pawlik, N.; Szpikowska-Sroka, B.; Pisarski, W.A. Energy Transfer Study on $\mathrm{Tb}^{3+} / \mathrm{Eu}^{3+}$ Co-Activated Sol-Gel Glass-Ceramic Materials Containing $\mathrm{MF}_{3}(\mathrm{M}=\mathrm{Y}, \mathrm{La})$ Nanocrystals for NUV Optoelectronic Devices. Materials 2020, 13, 2522. [CrossRef]

59. Fujihara, S.; Koji, S.; Kimura, T. Structure and Optical Properties of (Gd,Eu)F $\mathrm{F}_{3}$-Nanocrystallized Sol-Gel Silica Films. J. Mater. Chem. 2004, 14, 1331-1335. [CrossRef]

60. Velázquez, J.J.; Mosa, J.; Gorni, G.; Balda, R.; Fernández, J.; Pascual, L.; Durán, A.; Castro, Y. Transparent $\mathrm{SiO}_{2}-\mathrm{GdF}_{3}$ sol-gel nano-glass ceramics for optical applications. J. Sol-Gel Sci. Technol. 2019, 89, 322-332. [CrossRef]

61. Pawlik, N.; Szpikowska-Sroka, B.; Sołtys, M.; Pisarski, W.A. Optical properties of silica sol-gel materials singly- and doubly doped with $\mathrm{Eu}^{3+}$ and $\mathrm{Gd}^{3+}$ ions. J. Rare Earths 2016, 34, 786-795. [CrossRef] 
62. Szpikowska-Sroka, B.; Pawlik, N.; Goryczka, T.; Pisarski, W.A. Influence of silicate sol-gel host matrices and catalyst agents on luminescence properties of $\mathrm{Eu}^{3+} / \mathrm{Gd}^{3+}$ under different excitation wavelengths. RSC Adv. 2015, 5, 98773-98782. [CrossRef]

63. Pawlik, N.; Szpikowska-Sroka, B.; Pietrasik, E.; Goryczka, T.; Pisarski, W.A. Photoluminescence and energy transfer in transparent glass-ceramics based on $\mathrm{GdF}_{3}: \mathrm{RE}^{3+}(\mathrm{RE}=\mathrm{Tb}, \mathrm{Eu})$ nanocrystals. J. Rare Earths 2019, 37, 1137-1144. [CrossRef]

64. Secu, M.; Secu, C.E. Photoluminescence and energy transfer processes in Eu3+-doped SiO2-GdF3 oxyfluoride glass-ceramics prepared by sol-gel. manuscript in preparation.

65. Secu, C.E.; Bartha, C.; Secu, M. Dual up-conversion luminescence and magnetic properties of sol-gel derived Er3+/Yb3+ doped $\mathrm{SiO} 2-\mathrm{GdF} 3$ nano-glass ceramics. manuscript in preparation.

66. del Castillo, J.; Yanes, A.C.; Méndez-Ramos, J.; Velázquez, J.J.; Rodríguez, V.D. Structural and luminescent study in lanthanide doped sol-gel glass-ceramics comprising $\mathrm{CeF}_{3}$ nanocrystals. J. Sol-Gel Sci. Technol. 2011, 60, 170-176. [CrossRef]

67. Santana-Alonso, A.; Yanes, A.C.; Méndez-Ramos, J.; del Castillo, J.; Rodríguez, V.D. Sol-gel transparent nano-glass-ceramics containing $\mathrm{Eu}^{3+}$-doped $\mathrm{NaYF}_{4}$ nanocrystals. J. Non-Cryst. Solids 2010, 356, 933-936. [CrossRef]

68. Cruz, M.E.; Li, J.; Gorni, G.; Durán, A.; Mather, G.C.; Balda, R.; Fernández, J.; Castro, Y. Crystallization Process and Site-Selective Excitation of $\mathrm{Nd}^{3+}$ in $\mathrm{LaF}_{3} / \mathrm{NaLaF}_{4}$ Sol-Gel-Synthesized Transparent Glass-Ceramics. Crystals 2021, 11, 464. [CrossRef]

69. Velázquez, J.J.; Mosa, J.; Gorni, G.; Balda, R.; Fernández, J.; Durán, A.; Castro, Y. Novel sol-gel SiO $2-\mathrm{NaGdF}_{4}$ transparent nano-glass-ceramics. J. Non-Cryst. Solids 2019, 520, 119447. [CrossRef]

70. Cruz, M.E.; Li, J.; Gorni, G.; Durán, A.; Mather, G.C.; Balda, R.; Fernández, J.; Castro, Y. Nd ${ }^{3+}$ doped- $\mathrm{SiO}_{2}-\mathrm{KLaF}_{4}$ oxyfluoride glass-ceramics prepared by sol-gel. J. Lumin. 2021, 235, 118035. [CrossRef]

71. Yanes, A.C.; del-Castillo, J. Enhanced emission via energy transfer in RE co-doped $\mathrm{SiO}_{2}-\mathrm{KYF}_{4}$ nano-glass-ceramics for white LEDs. J. Alloys Compd. 2016, 658, 170-176. [CrossRef]

72. Kawamura, G.; Yoshimura, R.; Ota, K.; Oh, S.I.; Hakiri, N.; Muto, H.; Hayakawa, T.; Matsuda, A. A unique approach to characterization of sol-gel-derived rare-earth-doped oxyfluoride glass-ceramics. J. Am. Ceram. Soc. 2013, 96, 476-480. [CrossRef]

73. Secu, M.; Secu, C.E. Up-conversion luminescence of $\mathrm{Er}^{3+} / \mathrm{Yb}^{3+}$ co-doped $\mathrm{LiYF}_{4}$ nanocrystals in sol-gel derived oxyfluoride glass-ceramics. J. Non-Cryst. Solids 2015, 426, 78-82. [CrossRef]

74. Yanes, A.C.; Santana-Alonso, A.; Méndez-Ramos, J.; del-Castillo, J.; Rodríguez, V.D. Yb ${ }^{3+}-E^{3+}$ co-doped sol-gel transparent nano-glass-ceramics containing $\mathrm{NaYF}_{4}$ nanocrystals for tuneable up-conversion phosphors. J. Alloys Compd. 2009, 480, 706-710. [CrossRef]

75. Méndez-Ramos, J.; Yanes, A.C.; Santana-Alonso, A.; del-Castillo, J. Highly efficient up-conversion and bright white light in RE co-doped KYF4 nanocrystals in sol-gel silica matrix. Chem. Phys. Lett. 2013, 555, 196-201. [CrossRef]

76. Del-Castillo, J.; Yanes, A.C.; Abé, S.; Smet, P.F. Site selective spectroscopy in BaYF $: \mathrm{RE}^{3+}(\mathrm{RE}=\mathrm{Eu}, \mathrm{Sm})$ nano-glass-ceramics. J. Alloys Compd. 2015, 635, 136-141. [CrossRef]

77. Yanes, A.C.; del-Castillo, J. Bright luminescence of $\mathrm{Gd}^{3+}$ sensitized $\mathrm{RE}^{3+}$-doped $\mathrm{SiO}_{2}-\mathrm{BaGdF}_{5}$ glass-ceramics for UV-LEDs colour conversion. J. Alloys Compd. 2017, 695, 3736-3743. [CrossRef]

78. Del-Castillo, J.; Yanes, A.C. Ultraviolet and visible up-conversion in sol-gel based $\mathrm{SiO}_{2}-\mathrm{BaY}_{0.78-\mathrm{x}} \mathrm{Gd}_{\mathrm{x}} \mathrm{Yb}_{0.2} \mathrm{Tm}_{0.02} \mathrm{~F}_{5}$ nano-glassceramics. Opt. Mater. 2018, 84, 1-7. [CrossRef]

79. Yanes, A.C.; del-Castillo, J.; Luis, D.; Puentes, J. Novel $\mathrm{Sr}_{2} \mathrm{LuF}_{7}-\mathrm{SiO}_{2}$ nano-glass-ceramics: Structure and up-conversion luminescence. J. Lumin. 2016, 170, 789-794. [CrossRef]

80. Secu, M.; Secu, C.E. Up-conversion luminescence of $\mathrm{BaCl}_{2}: \mathrm{Er}^{3+}$ nanocrystals embedded in oxychloride nano-glass ceramic. J. Eur. Ceram. Soc. 2016, 36, 1699-1703. [CrossRef]

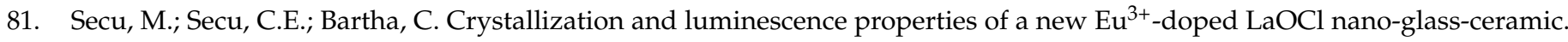
J. Eur. Ceram. Soc. 2016, 36, 203-207. [CrossRef]

82. Del Castillo, J.; Rodríguez, V.D.; Yanes, A.C.; Méndez-Ramos, J.; Torres, M.E. Luminescent properties of transparent nanostructured $\mathrm{Eu}^{3+}$ doped $\mathrm{SnO}_{2}-\mathrm{SiO}_{2}$ glass-ceramics prepared by the sol-gel method. Nanotechnology 2005, 16, S300-S303. [CrossRef]

83. Van Tran, T.T.; Turrell, S.; Capoen, B.; Le Van, H.; Ferrari, M.; Ristic, D.; Boussekey, L.; Kinowski, C. Environment segregation of $\mathrm{Er}^{3+}$ emission in bulk sol-gel-derived $\mathrm{SiO}_{2}-\mathrm{SnO}_{2}$ glass ceramics. J. Mater. Sci. 2014, 49, 8226-8233. [CrossRef]

84. Gonçalves, R.R.; Messaddeq, Y.; Chiasera, A.; Jestin, Y.; Ferrari, M.; Ribeiro, S.J.L. Erbium-activated silica-zirconia planar waveguides prepared by sol-gel route. Thin Solid Films 2008, 516, 3094-3097. [CrossRef]

85. Oikawa, M.; Fujihara, S. Sol-Gel Preparation and Luminescent Properties of $\mathrm{CeO}_{2}: \mathrm{Ln}\left(\mathrm{Ln}_{=} \mathrm{Eu}^{3+}\right.$ and $\left.\mathrm{Sm}^{3+}\right)$ thin films. J. Eur. Ceram. Soc. 2005, 25, 2921-2924. [CrossRef]

86. Jestin, Y.; Armellini, C.; Chiappini, A.; Chiaser, A.; Ferrari, M.; Goyes, C.; Montagna, M.; Moser, E.; Nunzi Conti, G.; Pelli, S.; et al. Erbium activated $\mathrm{HfO}_{2}$ based glass-ceramics waveguides for photonics. J. Non-Cryst. Solids 2007, 353, 494-497. [CrossRef]

87. Beall, G.H.; Borrelli, N.F.; Pinckney, L. Laser-Induced Crystallization of Transparent Glass-Ceramics. U.S. Patent No. 6928224, 9 August 2005.

88. Kajihara, K. Recent advances in sol-gel synthesis of monolithic silica and silica-based glasses. J. Asian Ceram. Soc. 2013, 1, 121-133. [CrossRef]

89. Tran, L.T.N.; Massella, D.; Zur, L.; Chiasera, A.; Varas, S.; Armellini, C.; Righini, G.C.; Lukowiak, A.; Zonta, D.; Ferrari, M. $\mathrm{SiO}_{2}-\mathrm{SnO}_{2}: \mathrm{Er}^{3+}$ Glass-Ceramic Monoliths. Appl. Sci. 2018, 8, 1335. [CrossRef]

90. Nogami, M.; Abe, Y. Enhanced emission from $\mathrm{Eu}^{2+}$ ions in sol-gel derived $\mathrm{Al}_{2} \mathrm{O}_{3}-\mathrm{SiO}_{2}$ glasses. Appl. Phys. Lett. 1996, 69, 3776-3778. [CrossRef] 
91. Nogami, M.; Abe, Y.; Hirao, K.; Cho, D.H. Room temperature persistent spectra hole burning of Sm ${ }^{2+}$-doped Silicate glasses prepared by the sol-gel process. Appl. Phys. Lett. 1995, 66, 2952-2954.

92. Cruz, M.E.; Duran, A.; Balda, R.; Fernandez, J.; Mather, G.C.; Castro, Y. A new sol-gel route towards $\mathrm{Nd}^{3+}-\mathrm{doped} \mathrm{SiO}_{2}-\mathrm{LaF}_{3}$ glass-ceramics for photonic applications. Mater. Adv. 2020, 1, 3589-3596. [CrossRef]

93. Li, Y.; Gecevicius, M.; Qiu, J. Long persistent phosphors-from fundamentals to applications. Chem. Soc. Rev. 2016, 45, 2090-2136. [CrossRef] [PubMed]

94. Riesen, N.; Pan, X.; Badek, K.; Ruan, Y.; Monro, T.; Zhao, J.; Ebendorff-Heidepriem, H.; Riesen, H. Towards rewritable multilevel optical data storage in single nanocrystals. Opt. Express 2018, 26, 12266-12276. [CrossRef]

95. Nagayama, S.; Kajihara, K.; Kanamura, K. Synthesis of nanocrystalline $\mathrm{LaF}_{3}$ doped silica glasses by hydrofluoric acid catalyzed sol-gel process. Mater. Sci. Eng. B 2012, 177, 510-514. [CrossRef]

96. Kemnitz, E.; Noack, J. The non-aqueous fluorolytic sol-gel synthesis of nanoscaled metal fluorides. Dalton Trans. 2015, 44, 19411-19431. [CrossRef] [PubMed] 